\title{
¿LIMITACIÓN O SUSPENSIÓN? UNA TEORÍA DE LOS LÍMITES \\ A LOS DERECHOS FUNDAMENTALES PARA EVALUAR LA ADOPCIÓN DE ESTADOS EXCEPCIONALES
}

\author{
Itziar Gómez Fernández \\ Profesora Titular de Derecho Constitucional, \\ Universidad Carlos III de Madrid. \\ Letrada del Tribunal Constitucional
}

Cómo citar este artículo / Citation: Gómez Fernández,I. (2021). ¿Limitación o suspensión?

Una teoría de los límites a los derechos fundamentales para evaluar la adopción de estados excepcionales. Garrido López, C. (coord.)

Excepcionalidad y Derecho: el estado de alarma en España, Colección Obras colectivas, Fundación Manuel Giménez Abad, Zaragoza. DOI: https://doi.org/10.47919/FMGA.OC21.0002

SUMARIO: I. LA RELEVANCIA DE UN DEBATE TEÓRICO SOBRE LAS NOCIONES DE SUSPENSIÓN Y LIMITACIÓN. II. IDENTIFICAR EL ELEMENTO CLAVE DE LA DISTINCIÓN ENTRE ESTADO DE ALARMA Y ESTADO DE EXCEPCIÓN: 1. Las situaciones que justifican la declaración del estado de alarma y del estado de excepción no son las mismas. 2. El procedimiento de declaración y subsiguiente control no es idéntico. 3. Las medidas susceptibles de ser adoptadas en ocasiones confluyen. III. IDENTIFICAR (O NO) EL ELEMENTO CLAVE DE LA DISTINCIÓN ENTRE LIMITACIÓN Y SUSPENSIÓN DE LOS DERECHOS FUNDAMENTALES. IV. UNA PROPUESTA DE CANON DE CONSTITUCIONALIDAD PARA EVALUAR EL REAL DECRETO DE DECLARACIÓN DEL ESTADO DE ALARMA LEJOS DE LA DICOTOMÍA LIMITACIÓN-SUSPENSIÓN. V. ALGUNAS NOTAS CONCLUSIVAS SOBRE LA DECLARACIÓN DEL ESTADO DE ALARMA 


\section{LA RELEVANCIA DE UN DEBATE TEÓRICO SOBRE LAS NOCIONES DE SUSPENSIÓN Y LIMITACIÓN}

La teoría de los límites de los derechos fundamentales es objeto de estudio constante y continuamente actualizado ${ }^{1}$, y referirnos a las ideas de limitación, restricción o suspensión de los derechos, en el contexto de la declaración de estados excepcionales, es participar en esa línea de trabajo teórico porque es reflexionar sobre las limitaciones constitucionalmente admisibles a los derechos constitucionalmente reconocidos, en contextos de excepcionalidad constitucional.

Desde que entramos en el s. XXI, la reflexión sobre los límites de los derechos ha estado profundamente relacionada con las situaciones de crisis global que han venido sucediéndose desde el atentado a las torres gemelas del 11 de septiembre de 2001 y con el recurso, por parte de los Estados, al derecho constitucional de excepción ${ }^{2}$. La garantía de la seguridad frente al riesgo del terrorismo se ha traducido, en un buen número de ordenamientos, en la adopción de medidas que introducen excepciones al régimen constitucional "ordinario", como fórmula para controlar el riesgo mediante la concentración de poderes o la restricción o suspensión de determinados derechos fundamentales ${ }^{3}$.

\footnotetext{
${ }^{1}$ Como trabajos monográficos destacaría los siguientes: BRAGE CAMAZANO, J., Los límites a los derechos fundamentales, Dykinson, Madrid, 2004; CASAL HERNANDEZ, J. M., , Los derechos fundamentales y sus restricciones, Legis, Venezuela, 2010; MUÑOZ ARNAU, J. A., Los límites de los derechos fundamentales en el derecho constitucional español, Aranzadi, Pamplona, 1998; VIDAL FUELLO, C., El juez ordinario como instancia de garantía ante los vacíos legales en materia de límites a los derechos fundamentales, Comares, Granada, 2010. Además, en nota al pie se expone un elenco nutrido de trabajos que se refieren a la cuestión de los límites, restricción o suspensión de los derechos fundamentales. Junto a ello, me parece de interés citar el análisis realizado por CIANCIARDO, J., "I limiti dei diritti fondamentali" (trad. al italiano de Sergio Gerotto), Ars Interpretandi, núm.7, 2002, pp. 218-239. En este trabajo se formula un análisis sobre las posiciones de la doctrina española en relación con el examen de los límites de los derechos fundamentales.

${ }^{2}$ Marc Carrillo se refiere a un "Derecho público sui generis". CARRILLO, M., Sistema de garantías y suspensión de los derechos y libertades en la Constitución española de 1978. Signo Ed., Barcelona, 1982, p. 73.

${ }^{3}$ A este respecto ACKERMAN, A., La Costituzione di emergenza: come salvaguardare libertà $e$ diritti civili di fronte al pericolo del terrorismo, Meltemi, Roma, 2005; MASFERRER, A., Estado de derecho y derechos fundamentales en la lucha contra el terrorismo: una aproximación multidisciplinar (histórica, jurídico-comparada, filosófica y económica), Aranzadi Thomson Reuters, Cizur Menor, Navarra, 2011; MORENO CATENA, V., CATALINA, M. A., "Limiting fundamental rights in the fight against terrorism in Spain", ¿A war on terror?: the European stance on a new threat, changing laws and human rights implications, Springer, New york, 2010, p. 443-466; REVENGA SÁNCHEZ, M (Dir.), Terrorismo y derecho bajo la estela del 11 de septiembre, Tirant Lo Blanch, Valencia, 2014; o SCHEININ, M. (Dir.), Terrorism and human Rights, Cheltenham, United Kingdom, 2013.
} 
La crisis financiera mundial, cuyo inicio podría situarse en la quiebra Lehman Brothers, el 15 de septiembre 2008, puso el acento en la necesidad de recuperar la estabilidad y equilibrio financieros, aun a costa de afectar severamente a los derechos laborales y a los derechos con alto contenido prestacional, como el derecho a la educación, el derecho a la asistencia sanitaria o el derecho a la vivienda, al tiempo que se optó por controlar el derecho a la protesta ante la progresiva movilización social ${ }^{4}$.

El último episodio de esta sucesión de crisis mundiales tiene nombre de virus -SARS-CoV-2- y alcance de pandemia. La restricción de la libertad deambulatoria, con todas las limitaciones conexas que se han visto asociadas, ha tenido por objeto declarado la preservación de la salud pública y el control de la enfermedad provocada por el virus, la covid-19. Así, la seguridad, la estabilidad o el equilibrio económico y la preservación de la salud, han sido las razones que han justificado la adopción de medidas restrictivas de derechos en todos los Estados constitucionales del mundo, y sería de sumo interés analizar la conexión entre cada una de esas crisis estructurales y el verdadero alcance de la limitación de derechos a ellas asociadas, así como la consolidación de muchas de esas restricciones como elementos estructurales del propio sistema de reconocimiento y garantía de los derechos subjetivos.

Pero la cuestión que ahora nos ocupa, mucho más modesta, se refiere a la diferenciación entre las nociones de limitación y suspensión de derechos fundamentales. $\mathrm{Y}$, se trata de una reflexión muy condicionada por el contexto normativo español y escasamente extrapolable a otros ${ }^{5}$, aunque pudiera parecer un debate esencialmente dogmático y por ello, susceptible de ser abordado desde aproximaciones comunes y generales. En realidad, si surge en nuestro sistema la discusión teórica sobre la necesidad de diferenciar claramente entre ambas nociones, es debido a la distinción de efectos que se asocian a la declaración de dos de los tres tipos de estados excepcionales previstos en la Constitución -el estado de alarma y el estado de excepción-, y a

\footnotetext{
${ }^{4}$ Sobre la crisis económica y sus efectos sobre los derechos fundamentales pueden consultarse las reflexiones contenidas en la obra colectiva BALAGUER CALLEJÓN, F., AZPITARTE SÁNCHEZ, M., SANCHEZ BARRILAO, J. F. (Dirs.), Los derechos fundamentales ante las crisis económicas y de seguridad en un marco constitucional fragmentado, Thomson Reuters-Aranzadi, Cizur Menor, Navarra, 2020.

${ }^{5}$ Da prueba de ello el examen de la regulación de los estados de emergencia en distintos países de nuestro entorno más cercano. Este examen es desarrollado, por ejemplo, en los trabajos de GAMBINO, S., SCERBO, A., "Diritti fondamentali ed emergenza nel costituzionalismo contemporaneo. Un'analisi comparata", Rivista di Diritto Pubblico Comparato ed Europeo, núm. 4, 2009.
} 
las severas críticas -políticas y teóricas- a que se ha visto sometida la opción de declarar el estado de alarma en España para controlar la expansión del coronavirus ${ }^{6}$.

Debe recordarse que, de la lectura combinada de los arts. 55 CE (contenido en el capítulo $5^{\circ}$ del Título I, relativo a la suspensión de los derechos y libertades) y 116 CE (contenido en el Titulo V, sobre las relaciones entre el Gobierno y las Cortes Generales), se deduce lo siguiente:

i) que la declaración de cualquiera de los tres tipos de estado excepcional (alarma, excepción y sitio) afecta esencialmente al alcance de los derechos fundamentales y a la división horizontal de poderes. Adicionalmente puede afirmarse que también se altera la aplicabilidad de determinadas normas del ordenamiento, eventualmente la propia Constitución, durante el tiempo en que dura la declaración del estado excepcional (en este sentido se afirma en el ATC 7/2012, de 13 de enero, FJ 4);

ii) que es una ley orgánica, en este caso la Ley Orgánica 4/1981, de 1 de junio, de los estados de alarma, excepción y sitio (LOEAES), la que regula y concreta los supuestos en que se declara cada uno de los estados excepcionales (art. 116.1 CE) ${ }^{7}$;

iii) que la Constitución solo establece las modalidades de tramitación de cada uno de los estados de emergencia -art. 116.2 CE para el estado de alarma, art. 116.3 CE para el estado de excepción, y art. 116.3 CE para el estado de sitio- mientras que las situaciones en las que cumple adoptar cada uno de esos estados (esto es el presupuesto habilitante) vienen definidas en la Ley Orgánica;

iv) en los tres supuestos, que la intervención conjunta del Gobierno y del Congreso de los Diputados en la toma de la decisión de acudir al derecho constitucional de excepción es determinante, aunque no sea idéntica la actuación de cada poder en cada uno de los supuestos;

\footnotetext{
${ }^{6}$ Véanse notas al pie $10,12,13$ y 14.

${ }^{7}$ En este sentido resulta de interés la cita de la STC 25/1981, de 14 de julio, en la que se define claramente que "la Constitución reserva a las Cortes Generales todo cuanto se refiere al desarrollo de los derechos fundamentales y de las libertades públicas, que constituyen el fundamento mismo del orden político-jurídico del Estado en su conjunto, como les reserva también su posible suspensión". Cierto es que tales consideraciones se referían al art. 55.2 CE, es decir a la suspensión individual de derechos fundamentales, pero esta consideración se puede extender sin dificultad a la suspensión general de los derechos.
} 
v) que, cuando se acuerde la declaración del estado de excepción o del estado de sitio (art. 55.1 CE), pueden ser suspendidos los derechos a la libertad personal (art. $17 \mathrm{CE}$, excepto en lo que hace a los derechos de la persona detenida en casos de declaración del estado de excepción); a la inviolabilidad del domicilio (art. 18.2 CE); al secreto de las comunicaciones (art. 18.3 CE); la libertad de circulación (art. 19 CE); a la libertad de expresión y la libertad de información [art. 20.1 a) y d) CE]; la prohibición del secuestro de comunicaciones (art. 20.5 CE); el derecho de reunión y manifestación (art. $21 \mathrm{CE}$ ); el derecho de huelga (art. 28.2 CE) y el de adoptar medidas de conflicto colectivo (art. 37. 2 CE). La lectura a sensu contrario del art. 55.1 CE, desarrollado en la LOEAES, es que no cabe la suspensión de cualquier otro derecho fundamental en ningún caso;

vi) y se contemplan, por último, que concurren una serie de garantías comunes a los tres estados de emergencia "para proteger al ordenamiento constitucional de las consecuencias que se pudieran derivar de la declaración de cualquier de ellos" (STC 83/2016, de 28 de abril, FJ 7), como la imposibilidad de interrumpir el funcionamiento de las Cortes Generales -lo que incluye la imposibilidad de disolverlas para llamar a elecciones- o de cualquier otro poder constitucional; la declaración expresa de mantenimiento de la responsabilidad de los integrantes del poder ejecutivo; 0 la prohibición de reforma constitucional durante la vigencia de cualquiera de los estados de emergencia (art. $169 \mathrm{CE})$.

De lo dicho parece deducirse que la suspensión de determinados derechos no está constitucionalmente prevista en los supuestos en los que se declare el estado de alarma, aunque puede caber si se decreta el estado de excepción. De ello deduce la doctrina que no es posible suspender el ejercicio de derechos fundamentales cuando se declare el estado de alarma y que solo es posible esa suspensión -respecto de los derechos específicamente citados en el art. 55.1 CE y en la ley orgánica de desarrollo-, cuando se declare el estado de excepción. El Tribunal Constitucional sostiene, en un obiter dictum claro de la sentencia 83/2016, de 28 de abril, que "a diferencia de los estados de excepción y de sitio, la declaración del estado de alarma no permite la suspensión de ningún derecho fundamental (art. 55.1 CE contrario sensu), aunque sí la adopción de medidas que pueden suponer limitaciones o 
restricciones a su ejercicio" (FJ 8). El mismo argumento es utilizado por el ATC $40 / 2020$, de 30 de abril, que, sin embargo, no lo utiliza para cuestionar el alcance del Real Decreto 463/2020, de 14 de marzo, por el que se declara el estado de alarma para la gestión de la situación de crisis sanitaria ocasionada por la covid-19, limitándose a evaluar si la aplicación de dicho Decreto supone un exceso en la restricción del ejercicio del derecho de manifestación $n^{8}$. Pero ni uno ni otro pronunciamiento explican cuál es el contenido de la noción de suspensión a la que se acogen, y parecen dar por supuesto que, si se ha declarado el estado de alarma, las restricciones de derechos contenidas en el decreto que procede a formular dicha declaración, son limitaciones y no suspensión de los mismos porque, "no cabe la suspensión en caso de declaración del estado de alarma". En suma, el argumento ciego del Tribunal no permite comprender la diferenciación de efectos que la Constitución asocia a la declaración, por un lado, del estado de alarma, y por otro del estado de excepción.

La conclusión sucesiva que se extrae aquí -en este caso ya sólo por una parte de la doctrina ${ }^{9}$ - es que, si se declara el estado de alarma estableciéndose como medida la restricción de uno o más derechos que suponga, de facto, su suspensión, entonces hubiera sido necesario proclamar el estado de excepción, que es el único que formalmente contempla la posibilidad de suspensión, resultando de este razonamiento un juicio claro de inconstitucionalidad frente al Real Decreto 463/2020.

Surgen, entonces, varias preguntas complejas y sin solución evidente en la jurisprudencia preexistente del Tribunal Constitucional: ¿el Real Decreto 463/2020, por el que se declara el estado de alarma para la gestión de la situación de crisis sanitaria ocasionada por la covid-19, es contrario a la prohibición implícita del art. 55.1 CE de suspender derechos fundamentales en

\footnotetext{
${ }^{8}$ El auto formula un juicio implícito de constitucionalidad del Decreto asumiendo que el mismo no prevé una suspensión de derechos, porque, de haberlo entendido así, hubiera debido admitirse a trámite el recurso de amparo, seguramente hubiera debido estimarse la solicitud de adopción de la medida cautelar interesada en aquel caso -esto es hubiera debido permitirse la celebración de la manifestación comunicada para su desarrollo el 1 de mayo, vigente aún la fase más restrictiva del estado de alarma- y, posteriormente, hubiera sido preciso tramitar el amparo y, conclusa su tramitación, hubiera debido elevarse cuestión interna de constitucionalidad sobre el Decreto. Quizá se impuso en la Sala 1aㅡ del Tribunal Constitucional la prudencia a la hora de solventar las particularidades del caso concreto, y quizá no se esté a este juicio implícito de constitucionalidad al resolver el recurso de inconstitucionalidad planteado contra el Real Decreto 463/2020, existiendo muchas dudas sobre la naturaleza de precedente de dicho auto.

${ }^{9}$ Véase nota al pie 13.
} 
la "mera" declaración del estado de alarma?; ¿este Real Decreto ha suspendido, pese a negarlo de forma explícita, la libertad deambulatoria, incurriendo por tanto en inconstitucionalidad al no haber seguido el procedimiento propio de la declaración del estado de excepción?

El intento por dar respuesta a estos interrogantes nos lleva al corazón del problema teórico: ¿cuándo estamos ante la limitación y cuándo ante la suspensión de un derecho fundamental?, ¿en qué momento se salta de la introducción de límites severos, que sería posible establecer con la declaración de la considerada como menos "intensa" de las situaciones de emergencia, a la suspensión de derechos, solo posible mediante el recurso a la declaración del estado de excepción?

La cuestión dista de ser exclusivamente teórica, habiendo adquirido una dimensión política notable, con una traducción inédita en la prensa ${ }^{10}$ durante los meses en que estuvo vigente la declaración del que hoy conocemos como "primer estado de alarma"11. No debe olvidarse que la crítica frente a las decisiones políticas en torno a las medidas adoptadas ha generado tensiones dialécticas y políticas en dos sentidos contrapuestos.

De un lado se encuentran los autores ${ }^{12}$ que defienden que la limitación de derechos que se ha producido, al menos durante la mayor parte del tiempo, es de naturaleza tal que resultaba innecesaria la declaración de cualquier estado de emergencia, incluido el de alarma, existiendo cobertura legal en las leyes ordinarias sectoriales de salud y seguridad, particularmente en la Ley Orgánica

\footnotetext{
${ }^{10}$ Efectivamente la discusión fue mediática y políticamente instrumentalizada. Pone el acento en esta cuestión el texto de BASURTO BARRIO, A. y BILBAO URIARTE, I., "La delgada línea entre alarma y excepción", en el Blog Hay Derecho, 3 de septiembre de 2020. Disponible en: https://hayderecho.expansion.com/2020/04/03/delgada-linea-alarma-excepcion/

${ }_{11}$ Cabe recordar, ya en este punto de la reflexión, que denominamos "primer estado de alarma" al que se adoptó mediante el Real Decreto 463/2020, de 14 de marzo, por el que se declara el estado de alarma para la gestión de la situación de crisis sanitaria ocasionada por el covid-19. Por su parte, el "segundo estado de alarma" de alcance nacional se adoptó mediante el Real Decreto 926/2020, de 25 de octubre, por el que se declara el estado de alarma para contener la propagación de infecciones causadas por el SARS-CoV-2.

${ }_{12}$ Por todos DOMENECH, G., "La discutible prórroga del estado de alarma", en Blog Almacén del Derecho, 17 de mayo de 2020. Disponible en: https://almacendederecho.org/la-discutibleprorroga-del-estado-de-alarma. En realidad, este autor cuestiona la declaración del estado de alarma para adoptar medidas que no supongan confinamiento domiciliario general, pero si restricciones severas del derecho a la libertad de desplazamiento. En concreto en su artículo Gabriel Doménech critica la última prórroga del primer estado de alarma, y abre a partir de ahí la reflexión sobre la suficiencia de la legislación ordinaria (sectorial o sectorial de emergencia) para adoptar medidas restrictivas de la libertad deambulatoria.
} 
3/1986, de 14 de abril, de Medidas Especiales en materia de Salud Pública ${ }^{13}$. Dentro de este rango de opiniones lo más frecuente es encontrar también argumentos a favor de que las medidas restrictivas pueden ser adoptadas por las autoridades autonómicas ${ }^{14}$. En todo caso, habría que entender que siendo materialmente innecesaria la declaración del estado de alarma, esta podría considerare inconstitucional por ausencia del presupuesto habilitante, es decir, por falta de concurrencia de los presupuestos que justificarían la adopción del derecho constitucional de excepción. En el otro extremo, se identifican los autores ${ }^{15}$ que sustentan que la limitación de derechos es de naturaleza tal que supone en realidad la suspensión del ejercicio de estos, de modo que sería necesaria la declaración del estado de excepción, de lo que se derivaría que,

13 Junto a ella, modificada en su art. 4 por el Real Decreto-ley 6/2020, de 10 de marzo, por el que se adoptan determinadas medidas urgentes en el ámbito económico y para la protección de la salud pública, hablaríamos asimismo del art. 26 de la Ley 14/1986, de 25 de abril, General de Sanidad (LGS); del art. 54 de la Ley 33/2011, de 4 de octubre, General de Salud Pública (LGSP); de los arts. 28 y ss. de la ley 17/2015, de 9 de julio, del Sistema Nacional de Protección Civil, que prevé la figura de las "emergencias de interés nacional"; y del art. 22 y ss. de la Ley 36/2015, de 28 de septiembre, de Seguridad Nacional. La cuestión que se plantean los autores que defienden esta tesis es por qué razón es necesario acudir a la adopción de un estado excepcional ex art. $116 \mathrm{CE}$, si a través de la legislación ordinaria se podía declarar una situación de interés para la seguridad nacional (art. 22 LSN), adoptar medidas como la incautación o inmovilización de productos, suspensión del ejercicio de actividades, cierres de Empresas o sus instalaciones, intervención de medios materiales y personales (art. 26 LGS y 54 LGSP), así como adoptar medidas para el reconocimiento, tratamiento, hospitalización o control de las personas enfermas (art. 2 LOMESP). Esta duda es clave en la diferencia de posicionamiento de los autores, máxime si se tiene en cuenta que, tanto antes como después de la declaración del estado de alarma, se decretaron medidas de restricción de la libertad de desplazamiento sobre la base de la legislación ordinaria y de la legislación ordinaria de urgencia.

14 Defiende claramente la colaboración entre el Estado y las Comunidades Autónomas, pese al eventual solapamiento o redundancia competencial NOGUEIRA LÓPEZ, A., "Confinar el coronavirus: Entre el viejo Derecho sectorial y el Derecho de excepción", El Cronista del Estado Social y Democrático de Derecho, núm. 86-87, 2020 (dedicado a: Coronavirus y otros problemas), pp.22-31. En el mismo sentido DOMENECH, G., "La discutible prórroga del estado de alarma", en Blog Almacén del Derecho, 17 de mayo de 2020. Disponible en: https://almacendederecho.org/la-discutible-prorroga-del-estado-de-alarma

${ }^{15}$ Se manifiestan en este sentido, ALVAREZ DE MORA, J. L., "Razones de una prohibición general deambulatoria", en Blog Almacén de Derecho, 11 de abril de 2020. Disponible en: https://almacendederecho.org/razones-de-una-prohibicion-general-deambulatoria. ALEGRE AVILA, J. M., SÁNCHEZ LAMELAS, A., "Nota en relación a la crisis sanitaria generada por la actual emergencia vírica", en el Blog de la AEPDA. Disponible en: http://www.aepda.es/AEPDAEntrada-2741-Nota-en-relacion-a-la-crisis-sanitaria-generada-porla-actual-emergencia-virica.aspx; ARAGÓN REYES, M. "Hay que tomarse la Constitución en serio", en El País, 10 de abril de 2020. Disponible en: https://elpais.com/elpais/2020/04/09/opinion/1586420090_736317.html; ideas que reitera en "Covid 19-aproximación constitucional a una crisis", editorial en Revista General de Derecho Constitucional, núm. 32, abril, 2020; DIAZ REVORIO, F.J., "Cosas de juristas", en el Blog El Miradero, Disponible en: https://javierdiazrevorio.com/cosas-de-juristas/; FERNANDEZ DE GATA, 2020. 
siendo la declaración del estado de alarma insuficiente, devendría por ello inconstitucional.

$Y$ en este cruce de posiciones diversas, que también permite identificar a quienes consideran adecuada la declaración del estado de alarma para restringir con carácter general la libertad de desplazamientos contemplada en el art. $19 \mathrm{CE}^{16}$, sigue considerándose clave la discusión en torno al grado de afectación de los derechos fundamentales de los ciudadanos ${ }^{17}$. La graduación de la intensidad del impacto de las medidas de control del contagio del coronavirus, deviene en motivo de discusión esencial a la hora de determinar la forma más adecuada de adopción de esas medidas, habida cuenta, además, de que la forma determina la fórmula de control jurisdiccional las mismas ${ }^{18}$.

\footnotetext{
${ }^{16}$ Se cuentan entre estos autores, sin perjuicio de que puedan sostener también críticas más o menos severas respecto de cuestiones concretas relacionadas con la adopción del estado de alarma: BROTAT I JUBERT, R., "Estat d'alarma i confinament", en el Blog de la Revista Catalana de dret públic, 29 de abril de 2020. Disponible en: https://eapcrcdp.blog.gencat.cat/2020/04/29/estat-dalarma-i-confinament-ricard-brotat-i-jubert/; CARMONA, A., "El estado de alarma, ipor fin!", El País, 14 de marzo de 2020. Disponible en: (https://elpais.com/elpais/2020/03/13/opinion/1584124546_672346.html?ssm=TW_CC;

COTINO HUESO, L., "Confinamientos, libertad de circulación y personal, prohibición de reuniones y actividades y otras restricciones de derechos por la pandemia del coronavirus”, Diario La Ley, núm. 9606, Sección Doctrina, 2 de abril de 2020, Wolters Kluwer; DE LA QUADRA-SALCEDO, T., "Límite y restricción, no suspensión", en El País, 8 de abril de 2020; PRESNO LINERA, M., "El coronavirus SARS-CoV-2 en la sociedad del riesgo global: alarma y precaución", en el blog El derecho y el revés. Disponible en línea: https://presnolinera.wordpress.com/2020/03/11/el-coronavirus-sars-cov-2-en-la-sociedad-delriesgo-global-alarma-y-precaucion/; SAENZ ROYO, E. "La inconstitucionalidad de los confinamientos", en El Heraldo de Aragón, 23 de octubre de 2020. Disponible en línea https://www.heraldo.es/noticias/opinion/2020/10/23/la-inconstitucionalidad-de-los-

confinamientos-eva-saenz-royo-la-rotonda-1401472.html; TAJADURA, J., «Derecho de crisis y Constitución», El País, 20 de marzo de 2020. Disponible en línea: https://elpais.com/elpais/2020/03/16/opinion/1584364474_350250.html. Desde una aproximación iusfilosófica, niega que haya existido suspensión en este caso GARCíA FIGUEROA, A., "Estado de alarma, estado de excepción y libertad de circulación", en el Blog Almacén de Derecho, 8 de abril de 2020. Disponible en línea: https://almacendederecho.org/estado-de-alarma-estado-de-excepcion-y-libertad-de-circulacion.

${ }^{17}$ F. VELASCO CABALLERO define esta discusión como "el debate entre "suspensionistas" y "restriccionistas". Véase "El debate entre "suspensionistas" y "restriccionistas" y las enseñanzas de la psicología social", en el Blog de Francisco Velasco, 18 de abril de 2020. Disponible en: https://franciscovelascocaballeroblog.wordpress.com/2020/04/18/el-debate-entre-

suspensionistas-y-restriccionistas-y-las-ensenanzas-de-la-psicologia-social/

${ }_{18}$ Parece pertinente recordar en este punto que la STC 83/2016, de 28 de abril, siguiendo lo previamente establecido en el ATC 7/2012, de 13 de enero, estableció que los decretos de declaración del estado de alarma y de su prórroga, han de considerarse como decisiones 0 disposiciones con rango o valor de ley, por las razones que se desarrollan en la argumentación de la sentencia, de modo que tales decretos no pueden ser fiscalizados, de forma directa, más que por el Tribunal Constitucional, y no por la jurisdicción contencioso administrativa, tal y como se deriva, a contrario sensu, de los arts. 106 CE y 1 LJCA (FJ 11 de la STC 83/2016). Ello sin perjuicio de que "los actos y disposiciones que puedan dictarse en su aplicación puedan impugnarse ante la jurisdicción ordinaria en cada caso competente (art. 3.2 de la Ley Orgánica 4/1981) y los órganos judiciales puedan, al enjuiciarlos, promover cuestión de 
Estamos llamados a centrarnos, pues, en la cuestión de la medición o la categorización de la intensidad de la restricción de derechos.

\section{IDENTIFICAR EL ELEMENTO CLAVE DE LA DISTINCIÓN ENTRE ESTADO DE ALARMA Y ESTADO DE EXCEPCIÓN}

No obstante, antes de avanzar sobre la cuestión de la distinción entre suspensión y limitación de los derechos fundamentales, vale la pena precisar la verdadera trascendencia de esta dicotomía a la hora de determinar la preferencia por la adopción de uno u otro estado excepcional, o por el recurso a la legislación sectorial específica de situaciones de emergencia.

Para ello, conviene recordar que las situaciones que justifican la declaración de los estados excepcionales son bien distintas (a), que los procedimientos de adopción difieren para establecer distinto grado de intervención del poder legislativo en cada uno de ellos (b) y que, finalmente, las medidas concretas no tienen el mismo alcance (c).

Efectuada esta reflexión quedará por determinar si resulta más adecuado escoger la situación de urgencia que debe ser adoptada en función de la situación material que actúa como presupuesto de dicha adopción, o si es el grado de afectación de los derechos fundamentales que exige la situación material concreta que se enfrenta el elemento que debe condicionar la antedicha selección. Adelanto ya que, a mi juicio, es el presupuesto que justifica la adopción de un estado de emergencia el que determina la elección de la modalidad de este y que, una vez identificado, debe ajustarse a un determinado procedimiento para su tramitación y debe permanecer, en lo que hace a las medidas concretas que se adopten, dentro del margen establecido en la LO 4/1981, que es la disposición normativa que concreta el elenco de

inconstitucionalidad contra los actos, decisiones o resoluciones con valor de ley de los que son aplicación, cuando consideren que puedan ser contrarios a la Constitución (ATC 7/2012, FJ 3). Por consiguiente, la fiscalización por la jurisdicción constitucional de los Reales Decretos por los que se declara y se prorroga el estado de alarma no excluye, como no podría ser de otro modo, el control jurisdiccional por los Tribunales ordinarios de los actos y disposiciones que se dicten en su aplicación durante la vigencia del estado de alarma. Asimismo, las personas afectadas podrán interponer recurso de amparo constitucional, previo agotamiento de la vía judicial ordinaria, contra los actos y disposiciones dictados en aplicación de aquellos Reales Decretos cuando los estimen lesivos de derechos fundamentales o libertades públicas susceptibles de protección a través de este proceso constitucional, facultad que le confiere el art. 55.2 LOTC". 
medidas posibles asociadas a cada estado excepcional ${ }^{19}$. Esta posición se basa en la comprensión, sostenida por autores como Francisco Fernández Segado, de que cada uno de los tres estados de alarma se vinculan a situaciones cualitativamente distintas, y no son tres etapas de una misma situación de emergencia, cada una de ellas más intensa que la anterior en restricción de derechos o reasignación de los poderes del Estado ${ }^{20}$.

\section{Las situaciones que justifican la declaración del estado de alarma y del estado de excepción no son las mismas}

El estado de alarma puede ser declarado por el Gobierno cuando, en una parte o en todo el territorio nacional, se produzca alguna de las siguientes "alteraciones graves de la normalidad": a) catástrofes, calamidades 0 desgracias públicas, tales como terremotos, inundaciones, incendios urbanos y forestales o accidentes de gran magnitud; b) crisis sanitarias, tales como epidemias y situaciones de contaminación graves; c) paralización de servicios públicos esenciales para la comunidad, cuando no se garantice el funcionamiento de los servicios esenciales de la comunidad en el marco de la adopción de medidas de conflicto colectivo, o en el caso de una convocatoria de huelga; y d) en situaciones de desabastecimiento de productos de primera necesidad. Parece evidente que, en este caso, las alteraciones de la normalidad tienen que ver con situaciones catastróficas bien de índole natural, bien generadas por algunos ciudadanos y que producen situaciones de penuria material, de desabastecimiento $o$ de bloqueo de servicios esenciales. En cualquier caso, no se trata de situaciones en las que se ponga en riesgo de

\footnotetext{
${ }^{19}$ Vale la pena recordar que el derecho constitucional de excepción viene conformado por lo dispuesto en los arts. 55 y $116 \mathrm{CE}$, pero también por el desarrollo que hace de sendas previsiones constitucionales la LO 4/1981, que es parámetro clave de constitucionalidad de cualquier Real Decreto que se adopte para declarar cualquiera de los estados excepcionales previstos en la Constitución. Ningún sentido tiene introducir dudas sobre la naturaleza de parámetro de constitucionalidad de la LO 4/1981 alegando que posee el mismo rango que los Reales Decretos de proclamación de los estados excepcionales (véase nota al pie precedente), en la medida en que tampoco ofrece dudas que un Estatuto de Autonomía aprobado bajo la forma de ley orgánica, o un Reglamento Parlamentario, o incluso una ley de bases pueda ser considerada como parámetro de constitucionalidad de otras normas del ordenamiento a la hora de que el Tribunal formule un juicio de ajuste constitucional. El ambiguo alcance de la noción de bloque de constitucionalidad no viene sino a reforzar este argumento. A este respecto véase GOMEZ FERNÁNDEZ, I., "Redefinir el bloque de la constitucionalidad 25 años después", Estudios de Deusto: revista de la Universidad de Deusto, Vol. 54, núm. 1, 2006, pp.61-98.

${ }^{20}$ FERNÁNDEZ SEGADO, F., "La Ley Orgánica de los estados de alarma, excepción y sitio". Revista de Derecho Político, núm. 11, 1981, pp. 83-116, aquí p. 89.
} 
forma directa la organización o la mera existencia del estado constitucional, sino de situaciones que, para ser revertidas, exigen una organización del poder y una gestión de la ciudadanía -lo que puede incluir también una modificación del alcance de sus derechos- distinta de la que prevé la Constitución para situaciones ordinarias.

Por su parte el art. 13 de la LO 4/1981, establece que se adoptará el "estado de excepción", en aquellos supuestos en que "el libre ejercicio de los derechos y libertades de los ciudadanos, el normal funcionamiento de las instituciones democráticas, el de los servicios públicos esenciales para la comunidad, o cualquier otro aspecto del orden público, resulten tan gravemente alterados que el ejercicio de las potestades ordinarias fuera insuficiente para restablecerlo y mantenerlo". En este caso, la naturaleza de la amenaza es distinta, y afecta directamente al orden constitucional porque presupone una alteración del orden público de tal magnitud que sólo la declaración del estado de emergencia -que permite adoptar medidas que suponen una forma de ejercicio del poder ajeno al que se ejerce en situaciones ordinarias- permiten preconizar la recuperación de un estado de cosas sujeto de nuevo al mantenimiento del orden público.

El Real Decreto 463/2020, de 14 de marzo, por el que se declaró el Estado de alarma para la gestión de la situación de crisis sanitaria consideró que concurrían dos de los supuestos de declaración del estado de alarma: una crisis sanitaria (art. 4.b LO 4/1981) y una situación de desabastecimiento de productos de primera necesidad (art. 4 d) LO 4/1981). Por su parte el Real Decreto 926/2020, de 25 de octubre, por el que se declara el "segundo" estado de alarma ${ }^{21}$ para contener la propagación de infecciones causadas por el SARS-CoV-2, identifica como situación que justifique la declaración del estado de alarma la existencia de una situación de crisis sanitaria (art. 4.b LO 4/1981). Parece incontestable que, en ambos supuestos, se daba efectivamente la situación habilitante para la adopción del estado de alarma y que no existía -ni ha existido en ningún momento desde el mes de marzo de 2020- una situación de alteración del orden público que hubiera llevado a justificar la adopción del estado de excepción.

\footnotetext{
${ }^{21}$ Recuérdese que precedió a este el Real Decreto 900/2020, de 9 de octubre, por el que se declara el estado de alarma para responder ante situaciones de especial riesgo por transmisión no controlada de infecciones causadas por el SARSCoV-2, con carácter restringido a varios municipios de la Comunidad de Madrid. En todo caso, este Real Decreto también identifica como situación que justifique la declaración del estado de alarma la existencia de una situación de crisis sanitaria (art. 4.b LO 4/1981).
} 


\section{El procedimiento de declaración y subsiguiente control no es idéntico}

El estado de alarma es declarado inicialmente por el Gobierno central, mediante "decreto acordado en Consejo de Ministros" (art. 6 de la LO 4/1981), del que dará cuenta al Congreso de los Diputados (art. 8 LO 4/1981). Este, cuya naturaleza como disposición con valor de ley ha sido establecido por la jurisprudencia constitucional en el ATC 7/2012, de 13 de enero y la STC $83 / 2016$, de 23 de febrero, debe contener $^{22}$ : i) el ámbito territorial de aplicación -recuérdese que el art. 5 de la misma ley establece la posibilidad de que, cuando se de uno de los supuestos de declaración del estado de alarma en todo o parte del ámbito territorial de una Comunidad Autónoma, el Presidente de la misma puede solicitar del Gobierno la declaración de estado de alarma-; ii) la duración, que no podrá exceder de quince días; iii) y los efectos del estado de alarma 0 , dicho en otros términos, las medidas concretas que se adoptan bajo la cobertura de la declaración concreta.

Una vez pasados los quince días de la declaración inicial del estado de alarma, es posible que el Gobierno solicite una o más prórrogas al Congreso de los Diputados $^{23}$, que determinará, en la autorización, tanto el plazo de la prórroga -que ya no se somete a límite temporal alguno ni en la Constitución ni en la ley-, su alcance, y las condiciones concretas de su desarrollo y control

\footnotetext{
${ }^{22}$ Véase, en relación con esta misma cuestión, la nota al pie núm. 18. Respecto del actual estado de alarma se manifiestan en idéntico sentido, a la espera de ulteriores pronunciamientos del Tribunal Constitucional, la providencia de la Sección Primera de 23 de diciembre de 2020, y el Auto del Tribunal Supremo de 4 de mayo de 2020 (ATS 2478/2020), al inadmitir el recurso contencioso administrativo interpuesto contra el "Real Decreto 463/2020, de 14 de marzo, por el que se declara el estado de alarma para la gestión de la situación de crisis sanitaria ocasionada por el COVID-19 aprobado por el Consejo de Ministros, así como sus prórrogas establecidas por el R. D. 476/2020 y el R. D. 487/2020", así como contra "el Real Decreto 492/2020, de 24 de abril". El auto invoca su jurisprudencia previa a este respecto (Autos de 10 de febrero de 2011, de 9 de marzo de 2011, de 9 de junio de 2011, de 30 de mayo de 2011, de 5 de abril de 2011 y de 28 de noviembre de 2011, así como la sentencia de la Sección Séptima de 17 de febrero de 2014-a quien se atribuyen también la totalidad de los autos citados-), así como la jurisprudencia constitucional al respecto. En contra de esta interpretación jurisprudencial se han manifestado algunos profesores de Derecho Constitucional (F. J. DÍAZ REVORIO, C. FLORES JUBERÍAS, C. RUIZ MIGUEL, A. RUIZ ROBLEZO, J. M. VERA SANTOS) que firman el "Dictamen en torno a la competencia de la Sala Tercera de lo Contencioso-Administrativo del Tribunal Supremo para la tramitación y resolución del Recurso núm. 001 / 0000099 / 2020, emiten ante el TS Catedráticos de Derecho Constitucional".

${ }^{23}$ Sobre el alcance temporal de las prórrogas véase DOMENECH, G., "La discutible prórroga del estado de alarma", en Blog Almacén del Derecho, 17 de mayo de 2020. Disponible en: https://almacendederecho.org/la-discutible-prorroga-del-estado-de-alarma
} 
parlamentario ${ }^{24}$. Si bien este puede limitarse a ser el habitual de la acción de gobierno, nada impide que en función de la duración o de las circunstancias concretas vinculadas a la adopción se prevea un procedimiento de rendición de cuentas periódico, o un mecanismo de control parlamentario más específico ${ }^{25}$, ello siempre dentro del respeto a lo previsto en el art. 8 de la LO 4/1981, que establece la obligación del Gobierno de dar cuenta al Congreso de los Diputados del desarrollo de la declaración del estado de alarma, suministrando tanta información como se sea requerida, y notificando los decretos que dicte durante la vigencia del estado de alarma en relación con este ${ }^{26}$. Lo expuesto

${ }^{24}$ Tal y como se ha apuntado previamente, la adopción del estado de alarma para hacer frente a la pandemia del coronavirus se produjo mediante el Real Decreto 463/2020, de 14 de marzo, que, al prever una duración de quince días, fue prorrogado hasta en seis ocasiones. Las prórrogas sucesivas fueron adoptadas por acuerdos del Consejo de Ministros de 24 de marzo (autorizado por el Pleno de 25 de marzo, dando lugar al Real Decreto 476/2020, de 27 de marzo); de 7 de abril (autorizado por el Pleno de 9 de abril dando lugar al Real Decreto 487/2020, de 10 de abril); 21 de abril (autorizado por el Pleno de 22 de abril, dando lugar al Real Decreto 492/2020, de 24 de abril); 5 de mayo (autorizado por el Pleno de 6 de mayo dando lugar al Real Decreto 514/2020, de 8 de mayo); y 19 de mayo de 2020 (autorizado por el Pleno de 20 de mayo dando lugar al Real Decreto 537/2020, de 22 de mayo). La finalización del estado de alarma se establecerá mediante el Real Decreto 555/2020, de 5 de junio, por el que se prorroga el estado de alarma declarado por el Real Decreto 463/2020 por última vez, fijándose la terminación para la medianoche del día 21 de junio de 2020. Por su parte, en la segunda declaración del estado de alarma, el Real Decreto 926/2020, de 25 de octubre, establece una duración de 15 días, pero la prórroga de este, establecida por el Real Decreto 956/2020, de 3 de noviembre, se establece por un plazo de seis meses, de modo que -en el momento en que se redactan estas líneas- el estado de alarma se encuentra prorrogado y estará vigente hasta el 9 de mayo del 2021.

${ }^{25}$ La disposición adicional primera del Real Decreto 476/2020, de 27 de marzo, por el que se prorroga el estado de alarma por primera vez, introduce una modificación en la disposición adicional sexta al Real Decreto 463/2020, para incluir la siguiente previsión: "De acuerdo con lo establecido en el apartado uno del artículo octavo de la Ley Orgánica 4/1981, de 1 de junio, de los estados de alarma, excepción y sitio, el Gobierno remitirá semanalmente al Congreso de los Diputados información documental estructurada de la ejecución de las distintas medidas adoptadas y valoración de su eficacia para contener el virus covid-19 y mitigar su impacto sanitario, económico y social." A partir de ese momento empezó a aplicarse dicha medida, tal y como se recoge en la exposición de motivos del Real Decreto 555/2020, de 5 de junio, por el que se prorroga por sexta y última vez el estado de alarma declarado por el Real Decreto 463/2020, de 14 de marzo, en la que se constata que: "El Gobierno ha remitido semanalmente al Congreso de los Diputados la información requerida en cumplimiento de lo previsto en la disposición adicional sexta del Real Decreto 463/2020, de 14 de marzo. Junto a los informes aportados por el Centro de Coordinación de Alertas y Emergencias Sanitarias y la Red Nacional de Vigilancia Epidemiológica, se ha dado cuenta al Congreso de los Diputados del conjunto de disposiciones, órdenes, instrucciones y resoluciones adoptadas por las autoridades competentes delegadas y por el Consejo de Ministros. Asimismo, el Gobierno ha comparecido semanalmente para valorar la evolución de la situación." No obstante, lejos de las previsiones contenidas en los Reales Decretos, la práctica del control parlamentario ha puesto de manifiesto algunos fallos destacados por la doctrina. Véase, a este respecto FERNÁNDEZ RODRíGUEZ, J. J., "Cuestiones constitucionales sobre el estado de alarma en España y la pandemia del COVID-19", en IEEE.ES, Documento de opinión 43/2000.

${ }^{26} \mathrm{El}$ art. 14 del Real Decreto 926/2020, de 25 de octubre (segundo estado de alarma), prevé un mecanismo específico de rendición de cuentas, estableciendo que el Presidente del Gobierno "solicitará su comparecencia ante el Pleno del Congreso de los Diputados, cada dos meses, 
supone que, existiendo la previsión de una rendición de cuentas y control político razonable, y siempre que así lo acuerde Congreso de los Diputados en la autorización de la prórroga, la duración del estado de alarma puede ser mucho más larga que la de un estado de excepción, siempre en la lógica de que la recuperación de la situación de normalidad después de una catástrofe que genera dificultades materiales relevantes, puede exigir de un tiempo mayor que el control de una situación de desórdenes públicos, por graves que estos $\operatorname{sean}^{27}$.

En relación con el estado de excepción, el Gobierno tiene también la iniciativa, pero su adopción se verá condicionada a la obtención de la autorización previa por parte del Congreso de los diputados. La solicitud de autorización debe contener: i) la determinación de los efectos del estado de excepción, con mención expresa de los derechos cuya suspensión se solicita, que no podrán ser otros que los enumerados en el apartado uno del art. 55 CE; ii) una relación de las medidas a adoptar referidas a los derechos cuya suspensión específicamente se solicita; iii) el ámbito territorial del estado de excepción, así como duración del mismo, que no podrá exceder de treinta días; iv) y la cuantía máxima de las sanciones pecuniarias que la Autoridad gubernativa esté autorizada para imponer, en su caso, a quienes contravengan las disposiciones que dicte durante el estado de excepción (art. 13.2 LO 4/1981).

Si el Congreso autoriza la declaración del estado de excepción, el Gobierno procede a efectuarla mediante un decreto acordado por el Consejo de

para dar cuenta de los datos y gestiones del Gobierno de España en relación a la aplicación del Estado de Alarma", mientras que el Ministro de Sanidad hará lo propio, con periodicidad mensual, ante la Comisión de Sanidad y Consumo del Congreso de los Diputados. Se prevé asimismo que, transcurridos cuatro meses de vigencia de la prórroga, "la conferencia de presidentes autonómicos podrá formular al Gobierno una propuesta de levantamiento del Estado de Alarma, previo acuerdo favorable del Consejo Interterritorial del Sistema Nacional de Salud a la vista de la evolución de los indicadores, sanitarios epidemiológicos, sociales y económicos". Al mismo tiempo, establece un sistema de habilitación general en la disposición final primera que plantea algunas dudas. Esta disposición prevé que "durante la vigencia del estado de alarma declarado por este real decreto, el Gobierno podrá dictar sucesivos decretos que modifiquen lo establecido en este, de los cuales habrá de dar cuenta al Congreso de los Diputados, de acuerdo con lo previsto en el artículo octavo.dos de la Ley Orgánica 4/1981, de 1 de junio", disposición esta que prevé la información al Congreso de los decretos que dicte durante la vigencia del estado de alarma en relación con este, pero que no alude a los decretos de modificación del que declara el estado de alarma o lo prorroga.

${ }^{27}$ No obstante, la inexistencia de impedimentos legales a la adopción de prórrogas de larga duración, cuando se decreta el estado de alarma, no han sido pocas las críticas a la adopción de una prórroga de seis meses en el Real Véase al respecto, por ejemplo, la columna de RODRÍGUEZ, R., “¿Es constitucional el Decreto del nuevo estado de alarma?”, Confilegal, de 3 de noviembre de 2020. Disponible en: https://confilegal.com/20201103-opinion-esconstitucional-el-decreto-del-nuevo-estado-de-alarma/ 
Ministros. Siendo la forma que adopta la declaración del estado de excepción idéntica a la que declara el estado de alarma, y pudiendo añadir a su legitimidad el hecho de que ha sido previamente autorizada por el Congreso de los Diputados, no parece que pueda ponerse en duda su valor como norma con rango de ley, en el sentido considerado por la jurisprudencia constitucional (ATC 7/2012 y STC 83/2016) respecto del decreto que declara el estado de alarma ${ }^{28}$. Por tanto, parece razonable pensar que el control jurisdiccional sobre el decreto será el mismo que se prevé para el decreto que declara (o prorroga) el estado de alarma.

El art. 15 de la LO 4/1981 prevé que cualquier modificación de medidas necesaria durante la vigencia del estado de excepción exige nueva autorización del Congreso de los Diputados, siendo posible la terminación anticipada del estado de emergencia por decisión del Consejo de Ministros que deberá informar al Congreso inmediatamente. Por lo que hace no ya a la terminación anticipada, sino a la prórroga del estado de excepción, la misma es posible si el Congreso lo autoriza, pero, a diferencia de lo que acontece en relación con el estado de alarma, como ya hemos apuntado, la prórroga máxima posible es de 30 días, de modo tal que la duración total máxima del estado de excepción solo puede ser de dos meses.

\section{Las medidas susceptibles de ser adoptadas en ocasiones confluyen}

La declaración del estado de alarma o del estado de excepción supone la posibilidad de adoptar medidas destinadas a controlar o revertir la situación de emergencia que justifica la adopción del estado excepcional, por esa razón la LO 4/1981 asocia al estado de alarma medidas más vinculadas a la gestión de la crisis material, sin descartar aquellas que pueden suponer limitación del ejercicio de derechos, mientras que enlaza al estado de excepción la adopción de medidas claramente restrictivas (suspensivas según el art. $55 \mathrm{CE}$ ) de aquellos derechos fundamentales que, de ser ejercidos, podrían reforzar la situación de crisis y la alteración del orden público que ha llevado a la declaración del estado de excepción o, analizado desde otra perspectiva, de aquellos derechos cuyo ejercicio fuera de los márgenes constitucionales que los delimitan, pueden haber coadyuvado a que se produzca la situación de emergencia que ha llevado a justificar la adopción del estado de excepción.

${ }^{28}$ Véanse las notas al pie 18 y 22. 
Así, respecto del estado de alarma, el art. 9 LO 4/1981 prevé, en materia organizativa, que las autoridades civiles y policiales, los funcionarios y los trabajadores al servicio de cualquiera de las administraciones (central, autonómica o local) quedarán bajo mando de quien sea determinado como autoridad competente, con la particularidad de que si esa autoridad fuera el Presidente de una Comunidad Autónoma, este podrá requerir la colaboración de los Cuerpos y Fuerzas de Seguridad del Estado, que actuarán bajo la dirección de sus mandos naturales ${ }^{29}$.

Por lo que hace a la afectación de derechos fundamentales, los arts. 11 y 12 de la LO 4/1981, apuntado el margen que tiene el decreto de declaración del estado de alarma, contempla que puedan ser adoptadas medidas como: i) limitación de la circulación o permanencia de personas o vehículos en horas y lugares determinados, o condicionarlas al cumplimiento de ciertos requisitos (afectando al art. $19 \mathrm{CE})^{30}$; ii) requisa temporal de todo tipo de bienes

${ }^{29}$ El Real Decreto 463/2020, de 14 de marzo, estableció en su art. 4 que la autoridad competente, a los efectos del estado de alarma, sería el Gobierno, siendo autoridades competentes delegadas en sus respectivas áreas de responsabilidad: la Ministra de Defensa; el Ministro del Interior; el Ministro de Transportes, Movilidad y Agenda Urbana y el Ministro de Sanidad. También las medidas dirigidas a reforzar el Sistema Nacional de Salud en todo el territorio nacional, previstas en el art. 12 del Decreto se refieren a la reorganización del Sistema, estableciendo, entre otras cosas, que "todas las autoridades civiles sanitarias de las administraciones públicas del territorio nacional, así como los demás funcionarios y trabajadores al servicio de las mismas, quedarán bajo las órdenes directas del Ministro de Sanidad en cuanto sea necesario para la protección de personas, bienes y lugares, pudiendo imponerles servicios extraordinarios por su duración o por su naturaleza". Posteriormente, los Reales Decretos de prórroga del estado de alarma van ajustando a las medidas adoptadas la definición de las autoridades competentes hasta llegar al Real Decreto 555/2020, de 5 de junio, que establece la sexta y última prórroga, y designa como "autoridad competente delegada para la adopción, supresión, modulación y ejecución de medidas correspondientes a la fase III del plan de desescalada", en el ámbito de sus competencias, a quien ostente la Presidencia de la comunidad autónoma, "salvo para las medidas vinculadas a la libertad de circulación que excedan el ámbito de la unidad territorial determinada para cada comunidad autónoma a los efectos del proceso de desescalada". Por lo que hace al Real Decreto 900/2020, de 9 de octubre, determina que la autoridad competente será el Gobierno (art. 4), mientras que el Real Decreto 926/2020, de 25 de octubre, estatuye que la autoridad competente será el Gobierno de la Nación, aunque en cada comunidad autónoma y ciudad autónoma, la autoridad competente delegada será quien ostente la presidencia, siendo estas autoridades las competentes para dictar, por delegación del Gobierno de la Nación, cuanta disposición sea precisa para la aplicación de las medidas que se prevén en el Real Decreto.

${ }^{30}$ Esta limitación, a la que se hará posterior referencia con mayor grado de detalle, se recoge en el Decreto 463/2020 en el artículo 7. El Real Decreto 900/2020, de 9 de octubre, establece por su parte una limitación de la libertad de circulación que se limita al cierre perimetral de determinados municipios. Por último, el Real Decreto 926/2020, de 25 de octubre, centra la limitación de la libertad de circulación en establecer restricciones al desplazamiento de las personas en el horario nocturno (art. 5); en la posibilidad de establecer cierres perimetrales de determinados territorios (art. 6); y en la limitación del número de personas que pueden encontrarse por determinados motivos reunidas en espacios públicos (art. 7). Por lo que hace a la limitación de movimiento en horario nocturno esta se circunscribe al período que transcurre 
(afectando al art. 33.1 CE) e imposición de prestaciones personales obligatorias (relacionado con la previsión del art. $30.4 \mathrm{CE}$ ) ${ }^{31}$; iii) intervención de industrias, fábricas, talleres, explotaciones o locales de cualquier naturaleza, con excepción de domicilios privados, dando cuenta de ello a los Ministerios interesados (afectación del art. $38 \mathrm{CE}$, en relación con el art. $33 \mathrm{CE}$ ); iv) racionamiento del uso de servicios ${ }^{32}$ o el consumo de artículos de primera necesidad; v) aseguramiento del abastecimiento de los mercados ${ }^{33} \mathrm{y}$ el funcionamiento de los servicios de los centros de producción afectados por situaciones de desabastecimiento de productos de primera necesidad; vi) adopción de las medidas previstas en la normativa sectorial relativa a enfermedades infecciosas, protección del medio ambiente, aguas e incendios forestales, si se declara el estado de alarma por desastres naturales o crisis sanitarias; v) intervención de empresas y movilización de su personal (afectando al art. $38 \mathrm{CE}$ ), en el caso de declaración del estado de alarma por paralización de servicios públicos esenciales o desabastecimiento de productos de primera necesidad.

La declaración del estado de excepción, por su parte, permite suspender los derechos fundamentales que cita expresamente el art. 55.1 CE, con el alcance que prevén los arts. 16 a 27 de la LO 4/1981. La mera lectura de estos preceptos permite entender, como decíamos unos párrafos atrás, que dichas medidas tienen como objeto fundamental la limitación severa de determinados

entre las once de la noche y las seis de la mañana, dándose la oportunidad a las autoridades competentes delegadas para que ajusten ese horario en una hora más o menos tanto en la hora de inicio como en la de finalización. El cierre perimetral de las comunidades o ciudades autónomas se prevé con carácter general, sin perjuicio de que cada autoridad competente delegada pueda establecer idéntica limitación de movimientos para ámbitos territoriales geográficamente inferiores. Por último, el art. 7 del RD limita a seis el número de personas no convivientes que pueden permanecer juntas en espacios de uso público abiertos o cerrados o en espacios de uso privado, pudiendo verse reducido este número por las autoridades competentes delegadas, aunque también ampliado siempre que se den las condiciones que establece el art. 10 del Real Decreto.

${ }_{31}^{31}$ Se prevén, para el caso que nos ocupa, en el art. 8 del Decreto 463/2020.

32 Podría incluirse en este tipo de previsiones la adopción de medidas de contención en el ámbito educativo y de la formación (art. 9 del Decreto 463/2020); en el ámbito de la actividad comercial, equipamientos culturales, establecimientos y actividades recreativas, actividades de hostelería y restauración (art. 10 del Decreto 463/2020); todo lo relativo al uso de lugares de culto y ceremonias civiles y religiosas (art. 11 del Decreto 463/2020); y también las medidas relacionadas con la gestión del sistema de transportes (art. 14 del Real Decreto 463/2020).

${ }^{33}$ En este ámbito podrían incluirse las medidas para el aseguramiento del suministro de bienes y servicios necesarios para la protección de la salud pública (art. 13 del Decreto 463/2020); así como las previstas para garantizar el abastecimiento alimentario (art. 15 del Real Decreto 463/2020); el suministro de energía eléctrica, productos derivados del petróleo y gas natural (art. 17 del Real Decreto 463/2020) o la prestación de servicios esenciales relacionados con infraestructuras críticas (art. 18 del Real Decreto 463/2020). 
derechos fundamentales, conceptualizada como suspensión por el propio art. 55.1 CE. Así:

i) cabe la modificación de los plazos máximos de detención que contempla el art. 17.2 CE, ampliándolos incluso respecto de lo que se contempla para la suspensión individual de derechos (art. 16 LO 4/1981), y previendo una información al órgano judicial que no supone la autorización judicial de la detención, aunque sea una suerte de supervisión judicial de la misma. También en relación con el art. $17 \mathrm{CE}$, se prevé en el art. 30 LO 4/1981 la posibilidad de decretar la prisión provisional, durante el tiempo que dure la declaración del estado de excepción, respecto de las personas que hubieran protagonizado hechos contrarios al orden público o la seguridad ciudadana que pudieran ser constitutivos de delito, quedando los condenados por estos mismos hechos excepcionados de cualquier beneficio penitenciario durante la vigencia del estado de excepción;

ii) se contempla la entrada gubernativa en domicilio sin previa autorización judicial, frente a la previsión de inviolabilidad del domicilio prevista en el art. 18.2 CE (art. 17 LO 4/1981);

iii) también se prevé la intervención de comunicaciones sin previa autorización judicial, limitando así el derecho al secreto de las comunicaciones del art. 18.3 CE (art. 18 LO 4/1981);

iv) se admite la limitación de la libertad deambulatoria (art. $19 \mathrm{CE}$ ), contemplándose, en este caso, la posibilidad de "prohibir la circulación de personas y vehículos en las horas y lugares que se determine, y exigir a quienes se desplacen de un lugar a otro que acrediten su identidad, señalándoles el itinerario a seguir", asimismo podrían delimitarse zonas de seguridad o de exclusión, y podría preverse tanto la prohibición (o condicionamiento a la comunicación) como la obligación de desplazamiento de determinadas personas a o desde un lugar determinado, si estas personas ofrecen motivos fundados para ello relacionados con su peligrosidad para el mantenimiento del orden público;

v) en lo que hace a la libertad de prensa [art. 20.1 d) CE], el art. 21 LO 4/1981 contempla la posibilidad de suspender todo tipo de publicaciones, emisiones de radio y televisión, proyecciones, 
cinematográficas y representaciones teatrales, así como se prevé el secuestro gubernativo de publicaciones;

vi) respecto de los derechos de reunión y manifestación (art. $21 \mathrm{CE}$ ), se admite la posibilidad de prohibir su ejercicio (incluso mediante la entrada sin autorización judicial a los locales en los que se estén celebrando reuniones para disolverlas), o de introducir la autorización gubernativa previa al mismo (art. 22 LO 4/1981), salvo que se trate de reuniones orgánicas de los partidos políticos, los sindicatos y las asociaciones empresariales;

vii) se habilita, asimismo, en el art. 23 LO 4/1981, la posibilidad de prohibir las huelgas (art. 28.2 CE) y la adopción de medidas de conflicto colectivo (art. 37.2 CE);

viii) el art. 26 LO 4/1981 también prevé la posibilidad de ordenar la intervención de industrias o comercios que puedan motivar la alteración del orden público, así como el cierre provisional de salas de espectáculos, establecimientos de bebidas y locales de similares características, limitando con ello la libertad de empresa del art. 38 CE;

ix) por su parte se contempla la suspensión de los funcionarios o personal al servicio de una administración pública (art. 29 LO 4/1981), si con su conducta favoreciesen la actuación de los elementos perturbadores del orden, limitando con ello el derecho a ostentar una función pública (art. 23.2 CE);

x) adicionalmente, teniendo estas medidas menos conexión directa con la restricción del ejercicio de derechos fundamentales, se prevé la posibilidad de intervención de los transportes y su carga (art. 19 LO 4/1981); el establecimiento de controles de extranjería adicionales (art. 24 LO 4/1981); la fijación de control de armas (art. 25 LO 4/1981) y de determinados edificios, instalaciones, obras, servicios públicos e industrias o explotaciones de cualquier género (art. 27 LO 4/1981) ${ }^{34}$.

La descripción de las medidas que pueden ser adoptadas en los dos tipos de estados excepcionales expuestos permite comprobar que, si bien la Constitución y la ley orgánica parecen vetar la posibilidad de suspender

\footnotetext{
${ }^{34}$ En relación con la eventual protección de infraestructuras es necesario completar la previsión de la LO 4/1981 con las previsiones de la Ley 8/2011, de 28 de abril, por la que se establecen medidas para la protección de las infraestructuras críticas.
} 
derechos cuando se declara el estado de alarma, habiéndolo interpretado asimismo el Tribunal Constitucional, lo cierto es que resulta difícil explicar por qué razón "limitar de la circulación o permanencia de personas o vehículos en horas y lugares determinados, o condicionarlas al cumplimiento de ciertos requisitos" (art. 9 LO 4/1981), es "limitar" el derecho a la libertad deambulatoria en el marco del estado de alarma, y "prohibir la circulación de personas y vehículos en las horas y lugares que se determine, y exigir a quienes se desplacen de un lugar a otro que acrediten su identidad, señalándoles el itinerario a seguir" (art. 20 LO 4/1981) se reconduce a una "suspensión" del mismo derecho, contemplado en la declaración del estado de excepción.

Podemos decir que limitar no es lo mismo que prohibir, pero si la limitación va asociada al establecimiento de un sistema sancionador que controle el exceso en el ejercicio del derecho las diferencias se diluyen, y ciframos la concepción del alcance de la limitación en la eficacia del sistema sancionador o en el alcance de las excepciones a, en este caso, la libertad de desplazamientos. Como también reconoce Paloma Requejo: "lo cierto es que entre las medidas que puede adoptar la autoridad competente -el Gobierno o el Presidente autonómico, por delegación- ante catástrofes, accidentes de gran magnitud, crisis sanitarias, paralización de servicios públicos esenciales para la comunidad y situaciones de desabastecimiento de productos de primera necesidad, resulta imposible distinguir en algunos casos dónde termina la limitación de los derechos fundamentales, lícita y justificable ante las circunstancias descritas, y dónde empieza ilícitamente una suspensión reservada en exclusiva a los estados de excepción y de sitio"35. Veamos si la diferenciación es posible en el plano teórico, independientemente del derecho concreto sobre el que se proyecte esta, para analizar posteriormente si una eventual diferenciación teórica puede ser aplicada a la regulación concreta del ejercicio de un derecho en una declaración concreta de estado excepcional, para juzgar su corrección constitucional.

\footnotetext{
${ }^{35}$ REQUEJO RODRÍGUEZ, P., “¿Suspensión o supresión de los derechos fundamentales?”, Revista de Derecho Político, núm. 51, 2001, pp. 105-137, aquí p. 115. 


\section{III.IDENTIFICAR (O NO) EL ELEMENTO CLAVE DE LA DISTINCIÓN ENTRE LIMITACIÓN Y SUSPENSIÓN DE LOS DERECHOS FUNDAMENTALES}

Partimos de la idea de que cualquier reflexión sobre la suspensión o limitación de los derechos fundamentales se formula desde la teoría de los límites a esos derechos. Luis Aguiar define los límites, "en sentido general y omnicomprensivo", como "toda acción jurídica que entrañe o haga posible una restricción de las facultades que, en cuanto derechos subjetivos, constituyen el contenido de los citados derechos"36. La fijación de cuáles son las facultades que conforman el contenido del derecho sobre el que actúan los límites exige reflexionar en términos de límites intrínsecos, y desde un plano, propio de la teoría del derecho, que escapa a las pretensiones de estas páginas ${ }^{37}$. Por esa razón partiremos de que, desde el derecho constitucional positivo, las facultades que conforman el contenido del derecho son las que establece el texto de la Constitución, que también establece límites ${ }^{38}$, concretados por la jurisprudencia constitucional referida a cada derecho en particular. Por su parte, el legislador orgánico (si atendemos a lo que dispone el art. $81 \mathrm{CE}$ ), también tiene capacidad para definir límites ${ }^{39}$ cuando desarrolla los derechos fundamentales o formula, por ejemplo, leyes de seguridad ciudadana que

\footnotetext{
${ }^{36}$ AGUIAR DE LUQUE, L., "Los límites de los derechos fundamentales", Revista del Centro de Estudios Constitucionales, núm. 14, 1993, pp. 9-34, aquí p. 10.

${ }^{37}$ Esta dimensión de análisis es abordada, entre otros, por ASIS ROIG, R., "Sobre los límites de los derechos", en Derechos y libertades: Revista del Instituto Bartolomé de las Casas, núm. 3, 1994, pp. 111-130. También resulta sumamente interesante la reflexión de J. BRAGE CAMAZANO sobre el examen escalonado de los límites a los derechos fundamentales, que clasifica dichos límites. Cfr. Op.cit., pp. 75- 100.

${ }^{38}$ AGUIAR DE LUQUE, L., Op. Cit. p. 16.

39 J. C. DE BARTOLOMÉ CENZANO introduce un matiz interesante a este respecto, afirmando que delimitar el derecho fundamental es atribuirle definición constitucional, mientras que la limitación del derecho es la acción legislativa de constreñir el ámbito objetivo de un derecho o libertad cuando se reconoce constitucionalmente esa facultad como uno más de los elementos estructurales de ese derecho. Cfr. "Los límites de los derechos y las libertades. Evolución jurisprudencial del límite de orden en España (I)", Año 54, núm. 1870, 2000, págs. 1905-1932, aquí p. 1907). Se detiene también en la explicación de esta conceptualización, atribuyendo matices respecto de su consideración a las dos líneas doctrinales sobre el examen de los límites que examina en su trabajo CIANCIARDO, J., Op. Cit. J. M. CASAL HERNÁNDEZ, por su parte, se sitúa en la misma línea -que él califica como ligeramente autónoma respecto de la dogmática alemana a la que se refiere ampliamente en su trabajo, y también establece diferencias conceptuales entre delimitación, reservada a la Constitución, y referida a la potestad para definir el propio alcance del derecho, y limitación o restricción, potestad atribuida al legislador que puede reducir las posibilidades de ejercicio del derecho fundamental. Cfr., Op. Cit., pp. 55 y ss. J. BRAGE CAMAZANO, por su parte, habla de conformación (como cuasi sinónimo de delimitación) y de limitación. Cfr. Op. Cit. pp. 64-75. Cualquiera de estos autores reconoce que los conceptos abordados son ambiguos y permiten distintos grados de actuación del legislador, y de los jueces constitucionales, y que varían además de contexto en contexto jurídico político.
} 
pueden condicionar severamente su ejercicio, pero siempre dentro del "contralímite" que determina el respeto al contenido esencial del derecho fundamental (art. 53.1 CE) ${ }^{40}$.

En este marco general, es la propia Constitución la que prevé la posibilidad de introducir límites de distinta intensidad en el ejercicio de los derechos fundamentales cuando se recurre al derecho constitucional de excepción ${ }^{41}$, que viene conformado por los arts. 55 y 116 CE, así como por la LO 4/1981, que desarrolla las exiguas previsiones de la Constitución ${ }^{42}$, pero que no alcanza a explicar, como hemos expuesto, la diferencia entre las diversas modulaciones del ejercicio de derechos que prevé. Tampoco podemos acudir a ninguna sentencia constitucional que defina claramente la distinción conceptual entre suspensión y limitación de derechos fundamentales. Las pocas sentencias que han entrado a valorar cuestiones relativas a suspensión de derechos (SSTC 25/1981, de 14 de julio; 199/1987, de 16 de diciembre; y 71/1994, de 3 de marzo) han abordado la cuestión en relación con la conocida como legislación antiterrorista, y por tanto se han referido a las previsiones del art. 55.2 CE y no al art. 55.1, que ahora nos interesa. Pero, en cualquier caso, ninguna de ellas ha formalizado la distinción entre suspensión y limitación. Es más, la STC 25/1981, de 14 de julio, asumiendo que son dos nociones diversas, unifica su tratamiento al afirmar que tanto limitación como suspensión tienen dimensión nacional, y al afirmar que una u otra solo se justifican en una democracia "en aras de la defensa de los propios derechos fundamentales cuando

\footnotetext{
${ }^{40}$ Véanse, a este respecto, las reflexiones de Luis Aguiar sobre los límites de los límites en las que no sólo se detiene en la cuestión del respeto al contenido esencial, sino que también desgrana interesantes reflexiones sobre la motivación de la introducción de límites: AGUIAR DE LUQUE, L., Op. Cit. p. 25. Más en extenso se refiere a esta misma cuestión CASAL HERNANDEZ, J.M., Op. Cit., pp. 278-313.

${ }^{41}$ Soy consciente de que cuando utilizo esta expresión asumo la existencia de una suerte de bloque de la constitucionalidad que incluye la LO 4/1981, en la medida en que esta Ley Orgánica puede (y debe) actuar como parámetro de control de los decretos de declaración del estado de alarma o del estado de excepción. Esta posición seguramente entra en conflicto con la de B. ALÁEZ CORRAL, que se expone en el texto. que sostiene que "la suspensión conlleva, por tanto, la desconstitucionalización de la norma iusfundamental, cuyo régimen jurídico pasa a estar compuesto por las disposiciones de la LOEAES, las previsiones de declaración del estado de excepción o de sitio que la establecen, y cualquiera otras disposiciones legales de desarrollo que no se vieran desplazadas en su aplicación por las anteriores". Cfr. "El concepto de suspensión general de los derechos fundamentales", en LÓPEZ GUERRA, L. M., ESPÍN TEMPLADO, E. (Coord.), La defensa del estado: actas del I Congreso de la Asociación de Constitucionalistas de España, Tirant Lo Blanch, Valencia, 2004, pp. 233-246., aquí p. 243.

${ }^{42}$ Sobre los antecedentes históricos de la legislación de excepción véase CARRILLO, M., Sistema de garantías y suspensión de los derechos y libertades en la Constitución española de 1978. Barcelona: Signo Ed., 1982, pp. 73-75; y FERNÁNDEZ SEGADO, F., "Naturaleza y régimen legal de la suspensión general de los derechos fundamentales". Revista de Derecho Político, núm. 11-19, 1983, pp. 31-58, aquí p. 35.
} 
determinadas acciones, por una parte, limitan o impiden de hecho su ejercicio en cuanto derechos subjetivos para la mayoría de los ciudadanos, y, por otra, ponen en peligro el ordenamiento objetivo de la comunidad nacional, es decir, el Estado democrático".

Si la jurisprudencia no ayuda, no resulta más clarificadora la doctrina. Cándido Conde Pumpido intenta objetivar la diferencia de modulaciones identificando tres categorías: i) la privación del derecho, cuyo ejemplo paradigmático sería la imposición de una pena privativa de derechos, sería la máxima negación de un derecho fundamental; posee carácter concreto, porque recae sobre un derecho prefijado; naturaleza individual, afectando a una persona determinada; y se somete a la caución de estar judicializada, puesto que para proceder a la privación se exige una decisión judicial, fundada y adoptada a través de la garantía de un proceso; ii) la suspensión, supondría dejar sin efecto el carácter oponible erga omnes del derecho fundamental durante un plazo determinado, lo que significa que no puede invocarse el derecho frente a los actos de aquellos "a quienes excepcionalmente se les reconoce la potestad de invadir el derecho fundamental de que se trate"; frente a la supresión de derechos, la suspensión puede ser individual (legislación antiterrorista) o general (estados excepcionales); y permite reservar un resto de eficacia al derecho, ya que cabría su invocación contra la arbitrariedad en la invasión del derecho ${ }^{43}$; iii) la limitación del derecho, se encontraría en el escalón mínimo de restricciones y se definiría como la delimitación de las fronteras de ejercicio de cada derecho determinadas por la propia normativa reguladora del ejercicio del derecho, por el ejercicio de otros derechos o por las situaciones de crisis que son causa de la declaración de estados excepcionales ${ }^{44}$.

\footnotetext{
${ }^{43}$ Me parece interesante hacer notar que esta diferencia teórica entre privación y suspensión no se percibe en absoluto en la jurisprudencia constitucional que mezcla o conecta ambas modalidades restrictivas en el FJ 6 de la STC 71/1994, de 3 de marzo: "Ante todo, se hace preciso destacar cómo la medida en cuestión no es, por así decir, autónoma, sino que se hace depender de algo que no es sino, materialmente, una suspensión del goce de la libertad personal. En efecto, la suspensión en el ejercicio de la función o cargo público solo tiene lugar una vez "decretada la prisión provisional", de tal modo que, además, aquella solo se mantiene "mientras dure la situación de prisión". Sin que el derecho a la libertad personal, como tal derecho fundamental, sea "suspendido", la situación de prisión provisional, legalmente acordada, implica una medida cautelar particularmente gravosa para uno de los derechos fundamentales más preciados de la persona".

${ }^{44}$ CONDE-PUMPIDO FERREIRO, C., "La suspensión de los derechos fundamentales", en X Jornadas de Estudio-Introducción a los Derechos fundamentales. Ministerio de Justicia, Secretaría General Técnica, Centro de Publicaciones, Madrid, 1988, pp. 1959-2021.
} 
Según Soler Martínez, la limitación de derechos asociada al estado de alarma supone que los derechos no desaparecen, mientras que durante el estado de sitio dejan de estar provisionalmente en vigor ${ }^{45}$, lo que parece aproximarse a la posición de Benito Aláez, a la que se hará inmediata referencia.

Pero en realidad la mayoría de los autores no se detienen en formular una distinción clara entre limitación y suspensión. Frente a ello, lo que procuran es una definición o identificación de las características de la noción de suspensión, procurando con ello individualizar el concepto. Quizá eso sirva para separar suspensión y limitación si las definiciones fueran excluyentes. Veamos:

Benito Aláez ${ }^{46}$, afirma que la suspensión es la supresión temporal de la vigencia de una norma constitucional, lo que explica que deba ser prevista en la propia Constitución, única disposición formalmente capaz de prever sus propias excepciones aplicativas ${ }^{47}$. Este autor sostiene asimismo que "la suspensión conlleva, por tanto, la desconstitucionalización de la norma iusfundamental, cuyo régimen jurídico pasa a estar compuesto por las disposiciones de la LOEAES, las previsiones de declaración del estado de excepción o de sitio que la establecen, y cualquiera otras disposiciones legales de desarrollo que no se vieran desplazadas en su aplicación por las anteriores". Aláez parte de la idea de que la Constitución pierde su vigencia en aquello que viene a ser ocupado por el derecho de excepción, y que por tanto se trata de una desconstitucionalización de los derechos -en lo que ahora nos interesa-, y no de una mera desfundamentalización, que se contentaría con la supresión de la obligatoriedad de respetar su contenido esencial. Ese argumento se cierra con la apreciación de que, si se produce la desfundamentalización, es posible realizar un juicio de constitucionalidad más severo, basado en el canon del examen de proporcionalidad de la medida restrictiva (proporcionalidad entendida en sentido amplio), mientras que si se produce la desconstitucionalización sólo es posible un juicio de razonabilidad ${ }^{48}$.

\footnotetext{
45 SOLER MARTINEZ, J. A., "Estado de alarma, libertad religiosa y de culto", en Revista General de Derecho Canónico y Derecho Eclesiástico del Estado, núm. 53, 2020, lustel.

${ }^{46}$ ALÁEZ CORRAL, B., "El concepto de suspensión general de los derechos fundamentales", en LÓPEZ GUERRA, L. M., ESPÍN TEMPLADO, E. (Coord.), La defensa del estado: actas del I Congreso de la Asociación de Constitucionalistas de España, Tirant Lo Blanch, Valencia, 2004, pp. 233-246.

47 ALÁEZ CORRAL, B., Op. Cit, p. 243.

${ }^{48}$ Como se verá más adelante, entiendo que el canon posible y necesario es el de proporcionalidad, dentro del marco de lo previsto en la Constitución en la LO 4/1981, de modo que no coincido con las apreciaciones del profesor Aláez respecto de la naturaleza desconstitucionalizadora del derecho de excepción.
} 
Por su parte Álvarez de Mora, sostiene que "la complejidad esencial de la suspensión pudiera, en fin, solucionarse por la observación de los elementos que la constituyen en cuanto acción: 1. La relación de pendencia respecto de un hecho externo; 2. La primacía del hecho externo y sus bienes sobre lo suspendido y su bien; y 3 . La alteración esencial de las reglas que rigen de ordinario la cosa suspendida" ${ }^{49}$. Siempre en un intento de definir cuando se produce el tránsito de la limitación de derechos a su suspensión, García Figueroa $^{50}$ identifica el elemento de la ponderación, es decir, este autor afirma que un derecho es suspendido, y no sólo limitado, cuando pierde su carácter ponderable y entra en la esfera de la interdicción absoluta de ejercicio, no pudiendo ser aplicable entonces juicio de proporcionalidad alguno sobre la restricción determinada.

Fernández Segado, en un intento por definir la naturaleza de la suspensión general de derechos, afirma que esta no afecta per se "ni a la existencia ni a la validez de la norma, sino tan sólo a su eficacia. [...] la suspensión queda limitada a la eficacia de la norma, en el sentido de que esta deja de ser vinculante para el órgano que decreta la suspensión. De ahí que la suspensión de derechos no implique abrogación de la existencia del derecho objeto de la suspensión, sino tan sólo una restricción temporal en el ejercicio de tales derechos. No estamos, pues, en sentido estricto, ante una suspensión de derechos, sino, lo que terminológicamente resulta más exacto, ante una suspensión en el ejercicio de esos derechos". Y añade "Subsidiariamente, la suspensión lleva implícita la idea de una actuación administrativa que, al estar libre de las limitaciones normales, podrá decidir con mayor discrecionalidad. Ahora bien, tal actuación no es en absoluto libre, ni mucho menos arbitraria, pues en la mayoría de los supuestos será la ley la que establezca las facultades de que se puede revertir la autoridad administrativa para actuar de

\footnotetext{
${ }^{49}$ ALVAREZ DE MORA, J. L., "Razones de una prohibición general deambulatoria", en Blog Almacén de Derecho, 11 de abril de 2020. Disponible en: https://almacendederecho.org/razones-de-una-prohibicion-general-deambulatoria

${ }^{50}$ GARCÍA FIGUEROA, A., "Estado de alarma, estado de excepción y libertad de circulación", en el Blog Almacén de Derecho, 8 de abril de 2020. Disponible en: https://almacendederecho.org/estado-de-alarma-estado-de-excepcion-y-libertad-de-circulacion. El autor establece este criterio aplicándolo al supuesto de la declaración del estado de alarma, y la limitación de la libertad deambulatoria, y afirma "con todas las cautelas que nos impone todo dilema, cabe sostener que el principio iusfundamental de la libertad de circulación no ha sido suspendido; porque no ha perdido su carácter ponderable (i.e. no ha decaído el requerimiento de argumentar su desplazamiento en el caso concreto), dado que cabe interpretar el art. 7.1 del Real Decreto como una medida abierta a un ejercicio de ponderación y a la aplicación del principio de proporcionalidad asociado a la propia naturaleza de nuestros derechos fundamentales".
} 
uno u otra manera según la naturaleza de las circunstancias que se tengan que afrontar" ${ }^{\prime 21}$.

González Beilfuss se refiere a la intensidad de la restricción, afirmando que, en lugar de "acudir a conceptos como la "suspensión del ejercicio", la "regulación extraordinaria" de los derechos fundamentales" o la "alteración de su contenido o de sus garantías" resulte preferible referirse, desde u punto de vista material, a la posibilidad de restringirlos en mayor medida de lo que puede hacerse en circunstancias de normalidad"52, posibilidad ésta que, sin embargo, también se reconoce como limitada al enfrentarse al contralímite de la garantía del contenido esencial y, en todo caso, limitable desde el examen del principio de proporcionalidad.

La negación de la desaparición total del derecho, y su "mera" preterición o sometimiento a otros valores constitucionales, debido a necesidades urgentes y prioritarias es la formulación elaborada por Tomas de la Quadra-Salcedo ${ }^{53}$ que, además, niega que la suspensión se limite a dejar sin efecto las garantías sin tocar el ámbito material de los derechos, admitiendo con ello que la suspensión limita esencialmente el sistema de garantías de los derechos y, eventualmente -en función del derecho del que estemos hablando- su contenido sustantivo. Este autor afirma asimismo que la suspensión solo funciona frente al Estado, y no altera la eficacia de los derechos en las relaciones entre particulares, además de que "deja siempre campos abiertos al juego y el ejercicio normal de los derechos y no solo en las relaciones entre particulares sino también en las relaciones con el poder", para concluir que "la enorme labilidad de los derechos fundamentales y libertades públicas hace que la suspensión no pueda referirse más que a algunos aspectos de tales derechos (...) y con ello deja abierta la cuestión de si la intervención limitadora se ha producido en el campo propio de

${ }^{51}$ FERNÁNDEZ SEGADO, F., "Naturaleza y régimen legal de la suspensión general de los derechos fundamentales". Revista de Derecho Político, núm. 11-19, 1983, pp. 31-58, aquí p. 40.

${ }^{52}$ GONZÁLEZ BEILFUSS, M., "La suspensión general de derechos", en LÓPEZ GUERRA, L.M., y ESPÍN TEMPLADO, E., La defensa del Estado, Actas del I Congreso de la Asociación de Constitucionalistas de España, Tirant Lo Blanch, Valencia, 2004, págs. 261-274, aquí, p. 267. Adelantando un poco la reflexión que se realizará posteriormente, a mi juicio el hecho de que González Beilfuss considere oportuno aplicar el juicio de proporcionalidad al examen de la suspensión de los derechos fundamentales, que es un mecanismo de introducción de límite a los límites, no hace sino poder de manifiesto la dificultad de distinguir realmente entre las nociones de suspensión y limitación.

${ }^{53}$ DE LA QUADRA-SALCEDO FERNANDEZ DEL CASTILLO, T., "La naturaleza de los Derechos Fundamentales en Situaciones de Suspensión", Anuario de Derechos Humanos, núm. 2, Instituto de Derechos Humanos. Facultad de Derecho, Universidad Complutense, Madrid, 1983, pp. 427-472. 
la situación excepcional y además si, admitido que sea en ese campo, se trata de una medida estrictamente indispensable. Se trata, por tanto, de un problema de límites que alimenta una tensión y una problemática de garantía y control de los ámbitos subsistente del derecho" 54 .

Solozábal ${ }^{55}$ afirma que la limitación se distingue de la suspensión que es una privación temporal o episódica del ejercicio de los derechos, si bien las garantías de estos no desaparecen totalmente, pero "la protección debilitada de los mismos queda exclusivamente asegurada por la Ley Orgánica 4/1981 de los estados de alarma, excepción y sitio".

Un intento similar, e igualmente poco definitivo, podría deducirse del FJ 3 de la STC 71/1994, de 3 de marzo, cuando establece que la suspensión responde a "situaciones normativas temporales en las que el régimen de determinados derechos fundamentales no es el previsto como regular y ordinario, sino uno distinto, instaurado como respuesta a una amenaza específica al orden democrático"

La muestra de las posiciones escogidas prueba la ausencia de un criterio objetivo para demarcar de forma clara las fronteras entre la suspensión y la "mera limitación" de los derechos fundamentales. No poseemos un canon claro de enjuiciamiento ${ }^{56}$. No es posible objetivar la "intensidad de la limitación de los derechos", y si bien podríamos graduar la restricción de derechos yendo del desarrollo (que también podría ser denominado regulación o concreción del derecho) a la limitación, para llegar a la suspensión individual primero y general o colectiva después, alcanzando finalmente el nivel de privación de derechos, lo cierto es que nos resultaría sumamente complicado determinar con claridad

\footnotetext{
${ }^{54}$ DE LA QUADRA-SALCEDO FERNANDEZ DEL CASTILLO, T., Op. Cit., p. 467.

${ }^{55}$ SOLOZÁBAL ECHAVARRÍA, J. J., "Los límites de los derechos y el sistema normativo", Derecho Privado y Constitución, núm. 17, 2003, pp. 449-478, aquí p. 451-452.

${ }^{56}$ De hecho, no faltan los autores que, en cambio, asumen que la suspensión no es sino un supuesto específico o especial de limitación de derechos fundamentales. Es el caso de BRAGE CAMAZANO, J., Op. Cit. p. 425. Podría entenderse que sostiene una posición similar MARTINEZ CUEVAS, M. D., La suspensión individual de derechos y libertades fundamentales en el ordenamiento constitucional español: un instrumento de defensa de la Constitución de 1978, Editorial Comares, Granada, 2002. Esta autora no llega a diferenciar entre limitación y suspensión, pero utiliza en su obra la jurisprudencia constitucional sobre limitación de los derechos fundamentales y respeto a su contenido esencial para sustentar sus tesis sobre la suspensión individual de los derechos fundamentales, con lo que parece asumir, siquiera implícitamente, que no existe una nítida distinción entre ambos. Por su parte, otra de las monografías españolas citadas en la nota al pie 1, sobre el tema de los límites de los derechos fundamentales evita expresamente referirse al tema de la suspensión, alegando que es un problema distinto al de los límites. Cfr. MUÑOZ ARNAU, J. A., Op. Cit. p. 115, pero sin explicar en absoluto las razones de tal afirmación.
} 
el momento o situación de tránsito entre uno y otro estadio de la eventual restricción de derechos.

Ninguna de las pautas identificadas por los autores para distinguir una situación de la otra es realmente definitiva e incontrovertible. Por ejemplo, pudiendo asegurar que la suspensión se somete a un límite temporal y que durante esa fracción de tiempo se contempla una excepción en la aplicación de la Constitución, en su vigencia, que solo se justifica desde la óptica de la superación del estado de alteración del orden público que justifica el recurso a la misma, no podemos sostener que la limitación vinculada a la declaración del estado de alarma no cumpla idénticas condiciones: también es temporal, también afecta a la vigencia del texto constitucional generalmente aplicable y del mismo modo solo se justifica desde la voluntad de superación del estado de emergencia que justifica su dictado. En los dos casos se da una vinculación estrecha entre el hecho externo que justifica la adopción de las medidas (suspensivas o limitativas de derechos) y en los dos prima el hecho externo sobre el régimen habitual de reconocimiento y ejercicio de los derechos fundamentales. No aprecio diferencia alguna en este ámbito. Tan excepción de la norma constitucional es la aplicación del ordenamiento previsto por la declaración del estado de alarma, como lo es la aplicación del ordenamiento previsto para el estado de excepción, ambos, por lo demás, cubiertos por la previsión constitucional y del legislador orgánico ${ }^{57}$. No aprecio la diferencia entre considerar que en un caso el derecho no desaparece, mientras que en el otro deja de estar en vigor. A mi juicio en los dos casos se produce un desplazamiento del régimen constitucional ordinario, que se justicia de modo distinto, y que genera efectos diversos, pero que no se puede explicar en términos de permanencia o desaparición del sistema jurídico constitucional.

La suspensión de las garantías (que identifico con la carencia de oponibilidad erga omnes) tampoco parece ser un criterio diferenciador nítido. Aunque algunos autores, como hemos visto, se refieren a la suspensión de las garantías como criterio distintivo ${ }^{58}$, lo cierto es que sigue pudiéndose aplicar un

\footnotetext{
${ }^{57}$ Recuérdese lo que a este respecto afirma la STC 71/1994, de 3 de marzo: "De ahí las variadas cautelas de las que el art. 55.2 C.E. ha hecho preceder y acompañar a esta suspensión de derechos sin horizonte definido. Ha querido, en primer lugar, el constituyente que esta opción normativa se adopte mediante Ley Orgánica, es decir, mediante una mayoría coincidente, en el Congreso de los Diputados, con la exigida para la declaración del estado de sitio, con el grado de consenso, pues, de que hace rodear las opciones normativas y políticas más trascendentes, salvo contadas excepciones".

${ }^{58}$ En una reflexión cercana a la que aquí se plantea, Fernández Segado establece que hoy no cabe diferenciar entre suspensión de derechos y suspensión de garantías, porque en realidad 
amplio elenco de garantías normativas, institucionales y jurisdiccionales, si bien puede variar el alcance de las mismas o el momento en que esa garantía actúa. Sólo por poner un ejemplo: cuando hablamos de la suspensión del derecho a la inviolabilidad del domicilio del art. 17 LO 4/1981, no podemos afirmar que este suprime toda garantía de este derecho, pero sí es posible sostener que dichas garantías cambian respecto de las que actúan en tiempo ordinario. Este argumento es desarrollado, respecto de la suspensión individual, por la STC 199/1987, de 16 de diciembre, que no niega la existencia de garantías jurisdiccionales cuando se determina la suspensión individual, y que reconoce la necesaria intervención judicial (que contempla expresamente el art. 55.2 CE), afirmando que "no cabe sacrificar enteramente ninguno de los dos contenidos del art. 55.2 de la Constitución, ya sea la necesaria intervención judicial a la suspensión, ya sea esta última a la primera, pues la Constitución trata de hacer compatibles la suspensión de los derechos y la intervención judicial al respecto. Nos encontramos en un supuesto característico de aplicación del llamado «principio de concordancia práctica» que impone tratar de hacer compatible la suspensión de los derechos y la intervención judicial. Quiere ello decir que el respeto a la fuerza normativa de la Constitución exigiría mantener toda la eficacia posible de la intervención judicial que fuera compatible con la voluntad, también de la Constitución, de posibilitar una suspensión singular de estos derechos, teniendo en cuenta, además, que la finalidad del precepto es hacer posible esa suspensión, imponiendo, complementariamente y como garantía de esa suspensión, una intervención judicial que ha de hacerse en todo caso compatible con aquella. Ello supone que, en último extremo, pero sólo en último extremo, la «necesaria intervención judicial», debe modalizarse para asegurar la posibilidad de la suspensión." (FJ 7).

Es cierto que estas consideraciones se refieren al apartado segundo del art. 55, y no al primero, pero se refieren en todo caso a las garantías judiciales vinculadas a la suspensión, de modo que sería difícil justificar que la diferencia entre limitación y suspensión tenga que ver con el sistema de garantías, y en particular con las garantías jurisdiccionales, pero que esa diferencia no actúa

no se da la suspensión de estas últimas "ya que en modo alguno se debe admitir que la suspensión de derechos, motivada por una situación de emergencia, pueda suponer la derogación, inexistencia o aun desconocimiento, ni tan siquiera con carácter temporal, de un o unos determinados derechos fundamentales". FERNÁNDEZ SEGADO, F., "Naturaleza y régimen legal de la suspensión general de los derechos fundamentales". Revista de Derecho Político, núm. 11-19, 1983, pp. 31-58, aquí p. 35. 
cuando la suspensión es individual. Si se analiza de cerca la suspensión de derechos prevista en la LO 4/1981, constatamos, por poner un ejemplo, que la entrada en domicilio será posible sin autorización judicial previa "cuando sea necesario para el esclarecimiento de hechos presuntamente delictivos o para el mantenimiento del orden público", y no en cualquier supuesto, de modo que se vincula la suspensión del derecho a la finalidad de la declaración del estado de excepción; que los agentes de autoridad deben poseer una orden formal y escrita que justifique la entrada gubernativa, de modo que pueda ser controlada posteriormente la orden de entrada, la autoridad que adopta la decisión y los motivos que la justifican; que la entrada en domicilio prevé la presencia de su titular o personas allegadas, a las que se sumará la presencia de dos testigos ajenos a la familia -cuya presencia es obligatoria- que actuarán también de referente externo, se entiende que para dar testimonio en un eventual control judicial sucesivo, en el supuesto de que el titular del domicilio no pueda encontrarse en el registro; que se levantará acta de la inspección, que será firmada por los asistentes, y la autoridad gubernativa comunicará al juez competente la adopción de la medida y la documental derivada de la entrada en domicilio, de lo que se deduce que, a partir de ese momento, el órgano judicial tiene control sobre los efectos derivados de la misma. Por otro lado, nada impide al titular del domicilio incoar las acciones legales oportunas para contestar la legalidad de la entrada. Las garantías, por tanto, no han desaparecido, porque sigue existiendo la posibilidad de control judicial de la entrada en domicilio, si bien la naturaleza de este control ha cambiado (de ser previo pasa a ser posterior), y la posición del titular del derecho ha quedado debilitada respecto de la situación de normalidad.

\section{UNA PROPUESTA DE CANON DE CONSTITUCIONALIDAD PARA} EVALUAR EL REAL DECRETO DE DECLARACIÓN DEL ESTADO DE ALARMA LEJOS DE LA DICOTOMÍA LIMITACIÓN-SUSPENSIÓN

Como hemos intentado explicar en el apartado previo, centrarnos en la consideración del binomio limitación-suspensión para formular un juicio de constitucionalidad sobre la adecuación de las medidas adoptadas al declarar el estado de alarma no parece resultar excesivamente útil. Girar en torno a la definición y diferenciación de ambos conceptos es esencialmente retórico, y nos lleva, insisto en esa idea, en afirmaciones tautológicas que resulta 
imposible verificar desde el análisis factual. Si los estados excepcionales no se gradúan en intensidad porque sencillamente responden a situaciones fácticas diversas y a emergencias de naturaleza totalmente distinta, es difícil explicar las diferencias entre suspensión y limitación de derechos como una graduación en la intensidad o la injerencia en esos derechos. Así que nada obsta, para proponer un canon de constitucionalidad casi equivalente al que se emplea para valorar, con carácter general, el ajuste constitucional de las limitaciones de derechos. Dicho en otros términos, si la categorización dogmática limitaciónsuspensión, no nos permite identificar claramente las situaciones que responden a una u otra con carácter abstracto no queda más opción que modificar la perspectiva de análisis, formulando el canon de control del alcance de los estados excepcionales desde otra perspectiva, que supone la inclusión de la LO 4/1981 como parámetro de constitucionalidad de los decretos de declaración de los estados de emergencia.

i) Así, en un "primer estadio del juicio", sería preciso valorar si las medidas adoptadas se identifican claramente con las medidas de suspensión que prevé la LO 4/1981, y que han sido expuestas previamente $^{59}$. Si la coincidencia es clara, parece poco dudoso que estaremos ante la suspensión de derechos que prevé el parámetro de constitucionalidad aplicable a este caso concreto. A partir de aquí, se presupone que una medida de este tipo solo cabe en un decreto declarativo de estado de excepción, suponiendo un exceso constitucionalmente inadmisible su inclusión en cualquier otra norma, que no tendría cobertura constitucional (entendida esta, insisto, en sentido amplio).

\footnotetext{
${ }^{59}$ En un sentido similar se manifiesta Francisco Velasco cuando afirma que la tarea común de delimitación de los derechos fundamentales que se atribuye a la ley es la que cumple, para las situaciones de alarma dice él -aunque podría decirse para cualquier situación excepcional de las tres posibles-, la LOEAES. En relación concretamente con el estado de alarma dice Velasco: "En especial, el art. 11 a) LOEAES ha previsto expresamente, para el estado de alarma, la posibilidad de "limitar la circulación o permanencia de personas o vehículos en horas y lugares determinados, o condicionarlas al cumplimiento de ciertos requisitos". Además, el art. 12 LOEAES prevé, específicamente para emergencias sanitarias, la aplicación de todas las medidas restrictivas contempladas en las leyes de salud pública. En esto, la LOEAES ha hecho lo mismo que otras muchas leyes orgánicas que, habiendo razones de peso debidamente ponderadas, han excluido determinadas conductas del ámbito de legítimo ejercicio de un derecho fundamental". VELASCO CABALLERO, F., "¿Estamos ante una "suspensión" de derechos fundamentales? Más bien no", en el Blog de Francisco Velasco Disponible en: https://franciscovelascocaballeroblog.wordpress.com/2020/04/05/estamos-ante-unasuspension-de-derechos-fundamentales-mas-bien-no/
} 
ii) Si no se pudiera identificar claramente la medida como suspensiva, por falta de coincidencia con el dictado de la ley, sería preciso formular "un juicio de control objetivo para valorar un eventual exceso" "60. Y no encuentro razón para entender que ese canon deba ser distinto al que se aplica habitualmente para controlar la imitación de derechos fundamentales ${ }^{61}$, esto es: i) previsión normativa de la restricción o concurrencia del respeto al principio de legalidad ${ }^{62}$; ii) existencia de una finalidad constitucionalmente legítima que justifique la restricción o ajuste al "principio de justificación teleológica" ${ }^{63}$; iii) y formulación del juicio de proporcionalidad en sentido amplio, es decir: adecuación -entre el fin perseguido y los medios empleados para su consecución-, necesidad en el seno de una sociedad democrática -o alternatividad de la medida adoptada-; y proporcionalidad en sentido estricto ${ }^{64}$.

\footnotetext{
${ }^{60} \mathrm{Y}$ ese juicio, obviamente cabría tanto en el supuesto de declaración del estado de alarma, excepción o sitio. Paloma Requejo lo expresa en los términos siguientes: "Como principio general, cualquier medida que se tome con ocasión de la declaración de un estado excepcional, incluidas las relativas a la suspensión de derechos, deberá ser necesaria, adecuada y proporcional con el fin que se pretende, esto es, el restablecimiento de la normalidad perdida. Este finalismo también condiciona la temporalidad de la medida que, una vez adquiera vigencia desde su publicación, durará el tiempo que dentro de los márgenes constitucionales la declaración del estado de crisis considere imprescindible para superarlo". Cfr. REQUEJO RODRÍGUEZ, P., Op. Cit, p. 116.

${ }^{61}$ Véase el trabajo de BRAGE CAMAZANO, J., Op. Cit. en el que se refiere a los requisitos constitucionales de toda limitación a los derechos fundamentales aludiendo a la reserva de ley, y al principio de proporcionalidad en sentido amplio, en las páginas 311 y ss. de su monografía. En este mismo sentido el trabajo de MUÑOZ ARNAU, J. A., Op. Cit. pp. 63 y ss, refiriéndose expresamente a la doctrina del Tribunal Europeo de Derechos Humanos.

${ }^{62}$ Recuérdense a este respecto, por todos, los dictados de las SSTC 37/1989, de 15 de febrero, FJ 7; 52/1995, de 23 de febrero, FFJJ 4 y 5; 207/1996, de 16 de febrero; 49/1999, de 5 de abril, FJ 5; y 169/2001, de 16 de julio.

63 CABEZUDO BAJO, M. J., "La restricción de los derechos fundamentales", Revista de Derecho Político, núm. 62, 2005, pp.187-227, aquí p. 198.

${ }^{64}$ No me detendré en formular un análisis más en profundidad sobre el juicio de proporcionalidad y todas sus implicaciones. Me limitaré a citar, por todas la STC 57/1994, de 28 de febrero, donde se sintetiza esta doctrina del siguiente modo en su FJ 6: "Por ello, no es ocioso recordar aquí que los derechos fundamentales reconocidos por la Constitución sólo pueden ceder ante los límites que la propia Constitución expresamente imponga o ante los que de manera mediata o indirecta se infieran de la misma al resultar justificados por la necesidad de preservar otros derechos o bienes jurídicamente protegidos (SSTC 11/1981, fundamento jurídico $7^{\circ}$ y $2 / 1982$, fundamento jurídico $5^{\circ}$, entre otras). Ni tampoco que, en todo caso, las limitaciones que se establezcan no pueden obstruir el derecho fundamental más allá de lo razonable (STC 53/1986, fundamento jurídico 3o). De donde se desprende que todo acto o resolución que limite derechos fundamentales ha de asegurar que las medidas limitadoras sean necesarias para conseguir el fin perseguido (SSTC 62/1982, fundamento jurídico $5^{\circ}$ y $13 / 1985$, fundamento jurídico $2^{\circ}$ ), ha de atender a la proporcionalidad entre el sacrificio del derecho y la situación en la que se halla aquel a quien se le impone (STC 37/1989, fundamento jurídico $7^{\circ}$ ) y, en todo caso, ha de respetar su contenido esencial (SSTC 11/1981, fundamento jurídico 10웅
} 
iii) En este caso, quizá el elemento más determinante en el análisis debiera ser el vínculo de conexidad entre las medidas adoptadas y sujetas a juicio y la finalidad perseguida con la limitación de derechos que, en el caso de la declaración de estados excepcionales, no es sino la superación de la situación excepcional que ha llevado a la declaración del estado de alarma.

En el supuesto de que el estado de alarma haya venido justificado por una crisis sanitaria, podría entenderse que la introducción de condiciones para el ejercicio de un derecho-libertad se justifica claramente por el ejercicio o preservación del derecho a la salud (art. $43 \mathrm{CE}$ ), presupuesto del derecho a la integridad física y moral (art. $15 \mathrm{CE}$ ). De modo tal que la finalidad perseguida por la limitación de derechos es, per se, la garantía de otros derechos fundamentales, lo que refuerza la justificación de su necesidad constitucional.

iv) Si la medida no superase el juicio de proporcionalidad en sentido estricto podría llegarse a la conclusión de que el exceso coloca a dicha medida en el ámbito de la suspensión del derecho fundamental, incluso aunque no haya podido ser categorizada, en inicio, como medida suspensiva prevista en la LO 4/1981.

Ahora bien, si fallara el juicio de conexidad, la conclusión sería distinta. Se trataría en este caso de que, no existiendo conexión entre la finalidad perseguida por la declaración del estado de alarma y la medida adoptada, esta última carecería de presupuesto habilitante, pero ello no querría decir que hubiera sido apropiado acudir a la declaración del estado de excepción, si las causas materiales que habilitan para su declaración tampoco concurrían. Dicho, en otros términos, sería posible afirmar que una determinada medida adoptada en la declaración del estado de alarma excede del marco constitucional previsto sin que ello nos lleve necesariamente a afirmar que la cobertura existiría si, la misma medida, hubiera sido adoptada bajo la declaración del estado de excepción. Esta conclusión sería totalmente ajena al canon que tratamos de establecer como criterio objetivo de enjuiciamiento.

196/1987, fundamentos jurídicos 4ㅇ a 6º; 120/1990, fundamento jurídico 8o y 137/1990, fundamento jurídico $\left.6^{\circ}\right)$. Por lo que ha de analizarse, a la luz de esta doctrina, si una medida como la impugnada en el presente caso se halla justificada en la protección de exigencias públicas y si, en su caso, cumple la condición de ser proporcionada en atención a la situación de aquel al que se le impone". Adicionalmente me remito a la extensa reflexión al respecto contenida en el trabajo de CASAL HERNANDEZ, J. M., Op. Cit., pp. 188-248. 
A mi juicio un parámetro como el expuesto nos ofrece criterios más certeros y próximos a la garantía de la seguridad jurídica que un razonamiento en términos de categorización de una medida como suspensiva o limitativa de derechos, desde un examen abstracto de un par de conceptos cuya definición y cuya diferenciación mutua no está clara en absoluto.

Podría plantearse que el juicio de constitucionalidad se formulase desde la consideración de los límites al contenido esencial del derecho fundamental ${ }^{65}$, pero no creo que esa opción interpretativa ofreciese más certezas que el tipo de canon expuesto ${ }^{66}$. Es cierto que existen tres argumentos válidos para sostener esta opción: i) los decretos de declaración de los estados excepcionales son considerados, por la jurisprudencia constitucional, disposiciones con valor de ley; ii) si el decreto tiene valor de ley, y tanto la suspensión como la limitación de derechos actúan dentro de la teoría general de los límites de los derechos fundamentales, podría valorarse el examen del decreto desde la aplicación de la teoría de los límites a los límites, concretamente desde la valoración de la afectación al contenido esencial del derecho fundamental; iii) el juicio de constitucionalidad que realiza el Tribunal

\footnotetext{
${ }^{65}$ Así lo hace la STC 71/1994, de 3 de marzo, relativa, como hemos visto, a la suspensión individual de derechos ex art. 55.2 CE y al control de algunos preceptos de la Ley de enjuiciamiento criminal que desarrollan aquel precepto. De hecho, algunos autores sostienen que ambas fórmulas o cánones de control se superponen, siendo la garantía del contenido esencial el juicio de proporcionalidad en sentido estricto. Véase, a este respecto DIEZ PICAZO, L.M., "Desarrollo y regulación de los derechos fundamentales", Repertorio Aranzadi del Tribunal Constitucional, núm. 20/2001, 2002, (estudio).

${ }_{66}$ A este respecto resulta interesante la reflexión de M. J. CABEZUDO MAJO, que parece indicar que ambas fórmulas de razonamiento son complementarias, de modo que el análisis de proporcionalidad implica el cumplimiento de un presupuesto que justifica la restricción del derecho -apreciación con la que estoy de acuerdo-, y responde a un control positivo de la medida cuestionada, mientras que el examen relativo al contenido esencial supone un control negativo y subsidiario respecto del anterior que se activa una vez que se observa que la medida restrictiva se ajusta al supuesto de hecho del derecho fundamental no cumpliendo, en cambio, las exigencias dimanantes del principio de proporcionalidad. Cfr. Op. Cit. pp.191 y ss. Desde mi perspectiva no se trata de análisis sucesivos, sino de análisis que responden a lógicas distintas, tal y como expongo en el cuerpo del texto. Mi posición se acerca más a la de $X$. ARZOZ SANTISTEBAN, que establece claramente que "dos son las técnicas de control de los límites de los derechos fundamentales que se han consolidado en la jurisprudencia constitucional: el principio de proporcionalidad y el respeto al contenido esencial de los derechos fundamentales" Cfr. La concretización y actualización de los derechos fundamentales, Centro de Estudios Políticos y Constitucionales, Madrid, 2014, p. 84). Entiendo también que se trata de dos técnicas distintas, y no necesariamente complementarias, y estoy de acuerdo con todas sus valoraciones respecto a la escasa claridad del Tribunal Constitucional a la hora de asumir o avalar las distintas teorías existentes en relación con el contenido esencial de los derechos fundamentales. A mi juicio esta falta de concreción hace pensar en una inconsistencia de la jurisprudencia constitucional que me inclina por el uso de la técnica de la proporcionalidad. También parece manifestar su preferencia por el recurso al principio de proporcionalidad SOLOZÁBAL ECHAVARRÍA, J. J., Op. Cit., p. 473.
} 
Constitucional sobre las limitaciones a derechos contenidas en la ley 0 en normas con rango de ley suele ajustarse al examen sobre la afectación del contenido esencial del derecho fundamental afectado por la regulación sujeta a juicio ${ }^{67}$.

No obstante, siendo ciertas las tres consideraciones previas, no puede descartarse formular otro tipo de juicio de constitucionalidad por parte del Tribunal Constitucional. De hecho, la jurisprudencia constitucional nos ofrece un ejemplo cercano en el tiempo de este tipo de razonamiento ${ }^{68}$, que es elegido porque el Tribunal asume que la restricción de derechos que impone la norma tiene por finalidad la protección de otro derecho fundamental que también se encuentra presente en la regulación sometida a juicio, siquiera de forma implícita. En la STC 64/2019, de 9 de mayo, el Pleno del Tribunal Constitucional, en respuesta a una cuestión de inconstitucionalidad planteada respecto del art. 18.2.4 de la Ley 15/2015, de jurisdicción voluntaria, pone de manifiesto como la limitación del derecho fundamental a la intimidad de un menor de edad queda afectado por una norma -la disposición cuestionada-, cuya finalidad es garantizar el derecho a la tutela judicial efectiva de ese mismo menor, en su vertiente del derecho a que el menor sea oído en la adopción de decisiones que puedan afectarle, en el marco de un procedimiento jurisdiccional. En este caso el Tribunal obvia el juicio de constitucionalidad desde el análisis de la afectación al contenido esencial del derecho a la

${ }^{67}$ P. REQUEJO RODRÍGUEZ, desde un argumento distinto al que yo formulo, pero que puede resultar complementario, sostiene que la suspensión hace "inoperante" la garantía del contenido esencial del artículo $53 \mathrm{CE}$, que "no cumplirá su habitual función de garantía". Cfr. Op. Cit., pp. 112-113. Sin embargo, insiste en que suspensión "no es una 'desaparición absoluta' o supresión". Pese a que no exista la garantía del contenido esencial sostiene que cabrá un "control de constitucionalidad que comprobará si el sacrificio al que se somete al derecho llega al punto de provocar su desaparición y, de no ser así, si es razonable o proporcionado, según el caso, con la finalidad que se persigue". Cfr. Op. Cit. p 111 y 114).

68 Alguna otra sentencia establece también la posibilidad de formular un juicio de constitucionalidad de medidas legislativas desde el recurso al enjuiciamiento de la proporcionalidad de la misma. Véase la STC 99/2019, de 18 de julio que establece: "EI enjuiciamiento de la proporcionalidad de una medida legislativa, como presupuesto de constitucionalidad de la misma, se articula en dos fases (por todas, STC 60/2010, FJ 9): a) la primera parte de ese canon de control consiste en examinar que la norma persigue una finalidad constitucionalmente legítima; y b) la segunda parte implica revisar si la medida legal se ampara en ese objetivo constitucional de un modo proporcionado. Esta segunda fase de análisis exige, a su vez, verificar (por todas, STC 64/2019, de 9 de mayo, FJ 5), sucesivamente el cumplimiento de "la triple condición de (i) adecuación de la medida al objetivo propuesto (juicio de idoneidad); (ii) necesidad de la medida para alcanzar su objetivo, sin que sea posible su logro a través de otra más moderada con igual eficacia (juicio de necesidad) y (iii) ponderación de la medida por derivarse de ella más beneficios o ventajas para el interés general que perjuicios sobre otros bienes o valores en conflicto (juicio de proporcionalidad en sentido estricto)". 
intimidad personal (art. 18.1 CE) desde el momento en que constata que el eventual conflicto no se produce entre la regulación legal y las facultades esenciales del derecho contenidas en la Constitución, sino entre dos derechos fundamentales: uno cuya protección pretende la norma cuestionada y otro, del que es titular la misma persona, que se puede ver limitado por la norma cuestionada.

Teniendo en cuenta estas consideraciones, que comparto, entiendo que en el supuesto concreto ante el que nos encontramos, es decir ante la declaración de un estado de emergencia por razones de crisis sanitaria, resulta razonable formular el juicio de constitucionalidad en términos de proporcionalidad (en sentido amplio) de las medidas adoptadas, porque este juicio otorga una posición determinante en la argumentación a la finalidad que sustenta la adopción de las medidas, al soporte constitucional de esa finalidad y a la conexión entre la restricción de derechos sometida a juicio y el objetivo perseguido por esa decisión limitativa. Pero, además, porque este tipo de juicio permite tener presente, con mayor facilidad, la existencia de un eventual conflicto entre derechos ${ }^{69}$. Entiendo que un juicio absoluto sobre la afectación del contenido esencial, o sobre la valoración de si una determinada restricción es suspensiva o simplemente limitativa del ejercicio de derechos, dificulta la inclusión de estos elementos que entiendo deben estar presentes en el juicio de constitucionalidad ${ }^{70}$.

${ }^{69}$ En el análisis sobre este conflicto no podría obviarse la hipotética diferencia entre la consideración constitucional de los distintos derechos, de modo que habría que plantearse la relevancia que debería otorgarse al hecho de que el eventual conflicto se diera entre un derecho fundamental de la sección $1^{\underline{a}}$ del Capítulo $2^{\underline{a}}$ del Título I, y un principio rector (Capítulo $3^{\circ}$ ) 0 un derecho o libertad de la sección $2^{2}$ del Capítulo $2^{\circ}$ del Título I. Si admitimos que los derechos tienen el mismo "valor", el derecho a la salud al que se califica como principio rector (art. 43.2 CE) puede actuar como límite del derecho a la libertad deambulatoria (art. $19 \mathrm{CE}$ ). Pero si no se acepta que ambos tengan el mismo valor, aunque no posean el mismo conjunto de garantías, y presuponemos que su equivalencia parte de la regulación legal de los principios rectores, entonces la preservación de la salud no podría actuar como límite del derecho a la libertad deambulatoria, salvo que así se previera expresamente en la ley, o incluso en la Constitución. Pero esta es una cuestión que va más allá de la reflexión sobre la diferencia entre limitación y suspensión de los derechos, por lo que no nos detendremos en ella, sin perjuicio de dejarla apuntada porque pudiera resultar de interés. Por lo demás tampoco entraré aquí a cuestionar las diferencias existentes entre la noción de ponderación y de juicio de proporcionalidad, que ha hecho correr ríos de tinta jurídica. Me limitaré a apuntar que entiendo que en el juicio de proporcionalidad tal y como se expone en el texto es posible introducir consideraciones sobre la interacción entre derechos que vayan más allá del mero juicio de ponderación.

${ }^{70}$ En un sentido similar parece pronunciarse L. COTINO HUESO, favorable a recurrir a un juicio estricto de proporcionalidad para valorar las medidas contenidas en la declaración del estado de alarma. Cfr. "Confinamientos, libertad de circulación y personal, prohibición de reuniones y 
La realización de este tipo de juicio de constitucionalidad se ha manifestado como posible, y razonablemente útil, si acudimos al ejemplo de órganos de la jurisdicción constitucional de otros Estados europeos. Por acudir nada más a un ejemplo, la Décision no. 2020-800, de 29 de agosto, del Conseil Constitutionnel francés, llamado a pronunciarse sobre varios preceptos del Projet prorogeant l'état d'urgence sanitaire et complétant ses dispositions ${ }^{71}$, que adoptaba las medidas de cuarentena y aislamiento de personas contagiadas del virus SARS-CoV-2. En concreto, el Conseil recurre al canon que aquí se expone al formular el control previo sobre los arts. 3 y 5 del proyecto de ley, que modificaban los arts. L. 3131-15 y L. 3131-17 del código de salud pública para precisar el campo de aplicación y el régimen de las medidas de cuarentena, ingreso y aislamiento, susceptibles de ser adoptadas en caso de estado de urgencia sanitaria. Sus argumentos establecen que las medidas cuestionadas deben someterse al triple juicio de adaptación, necesidad y proporcionalidad en relación con las restricciones que comporta respecto del derecho a la libertad individual, destacando, como punto de partida del razonamiento, que la finalidad de las medidas es "prevenir la propagación de la enfermedad que ha provocado la catástrofe sanitaria", de modo que el legislador persigue un objetivo de valor constitucional como es la protección de la salud (parágrafo 34) y que este tipo de medidas solo pueden ser adoptadas en el marco de la declaración de un estado de emergencia sanitaria (parágrafo 35). A partir de aquí el Conseil desarrolla el resto del juicio de proporcionalidad considerando: que las medidas solo están dirigidas a determinadas personas (las que hayan estado en zonas de circulación de la enfermedad y que entren a territorio nacional) (parágrafo 36); que la decisión restrictiva de derechos es adoptada, de forma individual, por la autoridad gubernativa competente a través de una resolución en la que se contienen expresamente las vías de recurso jurisdiccional (parágrafo 37); que la persona puede elegir donde cumplir las medidas (parágrafo 38); y que esas medidas pueden concluir antes del término previsto si el estado de salud del interesado lo permite (parágrafo 39).

actividades y otras restricciones de derechos por la pandemia del coronavirus", Diario La Ley, núm. 9606, Sección Doctrina, 2 de abril de 2020, Wolters Kluwer,

${ }^{71} \mathrm{La}$ disposición, tras el pronunciamiento del Conseil, sería aprobada adoptando la forma de LOI $n^{\circ}$ 2020-546 du 11 mai 2020 prorogeant l'état d'urgence sanitaire et complétant ses dispositions. Disponible en:

https://www.legifrance.gouv.fr/dossierlegislatif/JORFDOLE000041896076/ 
También ha sido el canon aplicado por el Tribunal Constitucional en el ATC 40/2020 de 30 de abril de 2020 (FJ 4), que inadmitió el recurso de amparo planteado por la Central Unitaria de Traballadores/as (CUT) contra la resolución de 21 de abril de 2020 de la Subdelegación del Gobierno de Pontevedra, que no dio su conformidad a la celebración de una manifestación el 1 de mayo de 2020 en Vigo, amparándose en la vigencia del estado de alarma. Sin entrar a otros pormenores interesantes que plantea el auto, me limitaré a constatar que, sin entrar al análisis del Decreto de declaración del estado de alarma, aplica el canon clásico a la hora de valorar el alcance de los límites impuestos, en aquel supuesto, al derecho de manifestación. En el FJ 4 ii), afirma que la "limitación del ejercicio del derecho tiene una finalidad que no sólo ha de reputarse como legítima, sino que además tiene cobertura constitucional bastante en los arts. 15 CE (garantía de la integridad física de las personas) y $43 \mathrm{CE}$ (protección de la salud), ambos tan intensamente conectados que es difícil imaginarlos por separado, máxime en las actuales circunstancias", para proclamar acto seguido la necesidad de formular un juicio de proporcionalidad que, sin embargo, el auto no desarrolla en su totalidad, ni con el detalle que seguramente hubiera sido necesario, limitándose a saltar al último elemento de enjuiciamiento cual es el juicio estricto de proporcionalidad.

En cualquier caso, cabría preguntarse cuál podría ser el resultado si se aplicase este canon al Real Decreto 463/2020, de 14 de marzo ${ }^{72}$. Por poner un

\footnotetext{
${ }^{72}$ Debe recordarse que esta disposición es objeto del recurso de inconstitucionalidad núm. 2054-2020, planteado por más de 50 diputados del Grupo Parlamentario Vox. El recurso denuncia la inconstitucionalidad de los arts. 7, 9, 10 y 11 del Real Decreto 463/2020, de 14 de marzo, por el que se declara el estado de alarma para la gestión de la situación de crisis sanitaria ocasionada por el COVID-19, así como los Reales Decretos 465/2020, de 17 de marzo, y 492/2020, de 24 de abril, que modifican parcialmente el art. 7 del Real Decreto 463/2020; los Reales Decretos 476/2020, de 27 de marzo, 487/2020, de 10 de abril y 492/2020, que aprueban sucesivas prórrogas del estado de alarma; y adicionalmente la y Orden SND/298/2020, de 29 de marzo, por la que se establecen medidas excepcionales en relación con los velatorios y ceremonias fúnebres para limitar la propagación y el contagio por el covid19. Los diputados recurrentes denuncian que las normas impugnadas infringen los arts. 44 y 116 CE, así como el art. 4 LO 4/1981, y los derechos fundamentales que restringen hasta el punto de derogarlos o suspenderlo. Por lo que hace al "Segundo estado de alarma" el mismo también ha sido impugnado, mediante el recurso de inconstitucionalidad núm. 5342-2020 interpuesto por más de cincuenta diputados del Grupo Parlamentario de Vox, frente a los arts. 2.2 y $2.3 ; 5 ; 6 ; 7 ; 8 ; 9 ; 10$ y 14 del Real Decreto 926/2020, de 25 de octubre, por el que se declara el estado de alarma para contener la propagación de infecciones causadas por el SARS-CoV-2; los arts. 2, 4 y 5 de la Resolución de 29 de octubre de 2020, del Congreso de los Diputados, por la que se ordena la publicación del Acuerdo de autorización de la prórroga del estado de alarma declarado por el Real Decreto 926/2020; y el art. 2, disposición transitoria única y disposición final primera, apdos. Uno, Dos y Tres, del Real Decreto 956/2020, de 3 de noviembre, por el que se prorroga el estado de alarma declarado por el Real Decreto 926/2020. En este caso los motivos de impugnación se centran ya no solo en la vulneración de los 
ejemplo, si se aplicase a su art. $20^{73}$, que es el que ha resultado más polémico en la medida en que dio cobertura, en su primera versión, a un confinamiento domiciliario severo, podríamos constatar ${ }^{74}$ :

i) que las medidas adoptadas no se identifican claramente con las medidas suspensivas de la libertad deambulatoria previstas en el art. 20.1 y 2 de la LO 4/1981, que establecen lo siguiente: "Uno. Cuando la autorización del Congreso comprenda la suspensión del artículo diecinueve de la Constitución, la autoridad gubernativa podrá prohibir la circulación de personas y vehículos en las horas y lugares que se determine, y exigir a quienes se desplacen de un lugar a otro que acrediten su identidad, señalándoles el itinerario a seguir. Dos. Igualmente podrá delimitar zonas de protección o seguridad y dictar las condiciones de permanencia en las mismas y prohibir en lugares determinados la presencia de persona que puedan dificultar la acción de la fuerza pública". Las restricciones a la movilidad no se plantearon en términos de prohibición, sino en términos de permisión del desplazamiento en determinadas circunstancias, que ponían de

derechos fundamentales que restringe el Real Decreto, y que se consideran de nuevo suspendidos, sino que alcanzan también a la delegación a los presidentes autonómicos de la posibilidad de delimitar algunas de las medidas previstas -a las que por lo demás se imputa un alto grado de inconcreción-, a la excesiva duración de la prórroga

${ }^{73}$ Recuérdese la dicción literal de este precepto: "Artículo 7. 1. Durante la vigencia del estado de alarma las personas únicamente podrán circular por las vías de uso público para la realización de las siguientes actividades: a) Adquisición de alimentos, productos farmacéuticos y de primera necesidad. b) Asistencia a centros, servicios y establecimientos sanitarios. c) Desplazamiento al lugar de trabajo para efectuar su prestación laboral, profesional o empresarial. d) Retorno al lugar de residencia habitual. e) Asistencia y cuidado a mayores, menores, dependientes, personas con discapacidad o personas especialmente vulnerables. f) Desplazamiento a entidades financieras y de seguros. g) Por causa de fuerza mayor o situación de necesidad. h) Cualquier otra actividad de análoga naturaleza que habrá de hacerse individualmente, salvo que se acompañe a personas con discapacidad o por otra causa justificada. 2. Igualmente, se permitirá la circulación de vehículos particulares por las vías de uso público para la realización de las actividades referidas en el apartado anterior o para el repostaje en gasolineras o estaciones de servicio. 3. En todo caso, en cualquier desplazamiento deberán respetarse las recomendaciones y obligaciones dictadas por las autoridades sanitarias. 4. El Ministro del Interior podrá acordar el cierre a la circulación de carreteras o tramos de ellas por razones de salud pública, seguridad o fluidez del tráfico o la restricción en ellas del acceso de determinados vehículos por los mismos motivos".

${ }^{74}$ De algún modo este canon aglutina de forma lógica y sucesiva el conjunto de argumentos que negarían que el Real Decreto 463/2020 prevé la suspensión del derecho fundamental a la libertad deambulatoria. F. J. DÍAZ REVORIO congrega todos esos argumentos, para someterlos a crítica en la medida en que su posición es claramente favorable a la consideración de que el Real Decreto ha desnaturalizado la libertad deambulatoria, suspendiendo de facto su ejercicio. Cfr. "A vueltas con la suspensión de los derechos fundamentales", en el Blog Almacén de Derecho, 9 de abril de 2020. Disponible en: https://almacendederecho.org/a-vueltas-con-la-suspension-de-los-derechos-fundamentales 
manifiesto un elenco relativamente amplio de razones que justificaban el ejercicio de la libertad deambulatoria. Podríamos entrar a discutir si el planteamiento no era, al contrario, que existía una prohibición general de desplazarse sujeta a determinadas excepciones, pero lo que resulta indiscutible es que las medidas no encajan, de forma indubitada, en la previsión de suspensión, vinculada a la declaración del estado de excepción, que establece el art. 20 LOEAES.

ii) que las medidas adoptadas tienen cobertura normativa en el art. 11 a) LO 4/1981, que prevé la posibilidad de "limitar la circulación o permanencia de personas o vehículos en horas y lugares determinados, o condicionarlas al cumplimiento de ciertos requisitos".

iii) que las medidas adoptadas persiguen una finalidad constitucionalmente legítima, como es controlar la propagación de la enfermedad causante de la crisis sanitaria, esto es proteger, preventivamente, la salud de los ciudadanos (art. $43 \mathrm{CE}$ ) que se vincula, inescindiblemente a la preservación de su derecho a la vida y la integridad física (art. $15 \mathrm{CE}$ ).

iv) que las medidas adoptadas se adecúan a la finalidad perseguida, porque parece científicamente demostrado que el cese de contacto social o su reducción drástica, frena las curvas de propagación del virus.

v) que, con los datos disponibles y el estado actual de la ciencia, es difícil valorar la necesidad de la medida o, dicho, en otros términos, la inexistencia de medidas menos restrictivas del derecho comprometido, pero igualmente eficaces. En realidad, algo así vino a decir el Tribunal Constitucional en su ATC 40/2020, en un obiter dicta particularmente interesante, pronunciado al hilo de la explicación de la justificación de la medida restrictiva del derecho de manifestación: "Es aquí donde la finalidad de la medida restrictiva del ejercicio del derecho confluye con la justificación de la declaración del Estado de alarma. Las razones que sustentan ambas son idénticas y buscan limitar el impacto que, en la salud de los seres humanos, en su integridad física y en su derecho a la vida 
pueda tener la propagación del covid-19. En el estado actual de la investigación científica, cuyos avances son cambiantes con la evolución de los días, incluso de las horas, no es posible tener ninguna certeza sobre las formas de contagio, ni sobre el impacto real de la propagación del virus, así como no existen certezas científicas sobre las consecuencias a medio y largo plazo para la salud de las personas que se han visto afectadas en mayor o menor medida por este virus. Ante esta incertidumbre tan acentuada y difícil de calibrar desde parámetros jurídicos que acostumbran a basarse en la seguridad jurídica que recoge el art. 9.3 de la Constitución, las medidas de distanciamiento social, confinamiento domiciliario y limitación extrema de los contactos y actividades grupales son las únicas que se han adverado eficaces para limitar los efectos de una pandemia de dimensiones desconocidas hasta la fecha. Desconocidas y, desde luego, imprevisibles cuando el legislador articuló la declaración de los estados excepcionales en el año 1981".

vi) $Y$ que, si pudiéramos superar el juicio de necesidad, seguramente sería posible llegar a la conclusión de que la restricción de la movilidad, pese a ser severa, no resulta desproporcionada teniendo en cuenta la necesidad imperiosa de garantizar el derecho a la salud de la ciudadanía en el contexto de desabastecimiento de equipos médicos, materiales y humanos, existente en el momento en que se adoptaron las medidas cuestionadas. Me refiero, por ejemplo, a la saturación de los hospitales ante la insuficiencia de pericia médica constatada en aquel momento para hacer frente a la sintomatología diversa, y en parte desconocida, que presentaba el virus; a la inexistencia de mascarillas suficientes en el mercado para que pudieran ser utilizadas por la mayoría de la población como gesto barrera para evitar o minimizar las posibilidades de contagio, y la inexistencia de protocolos sanitarios y de seguridad suficientemente desarrollados en aquel momento para permitir la continuidad de los contactos sociales previamente existentes. $\mathrm{Y}$ vuelvo de nuevo al obiter dicta del ATC 40/2020 que acabo de reproducir literalmente. 


\section{ALGUNAS NOTAS CONCLUSIVAS SOBRE LA DECLARACIÓN DEL ESTADO DE ALARMA}

No es fácil formular un juicio de constitucionalidad completo sobre el Real Decreto 463/2020, de 14 de marzo. Ni parece prudente desde mi posición actual como Letrada del Tribunal Constitucional habida cuenta de que se encuentra pendiente de resolución el recurso de inconstitucionalidad núm. 2054-2020, planteado contra dicha disposición. Me he limitado a esbozar un canon y darle una aplicación muy superficial a una medida muy concreta contenida en el Decreto, sobre la que otros antes que yo se han manifestado de forma diversa.

Pero sí considero necesario sintetizar alguna de las ideas expuestas en este trabajo, aunque sólo sea para ofrecer claves retrospectivas de lectura.

Entiendo que la causa material concurrente justificaba la adopción del estado de alarma, porque estábamos (y seguimos estando) ante una crisis sanitaria, con alcance no ya de epidemia, como prevé la LO 4/1981, dino de pandemia. También concurría en aquel momento ( $\mathrm{y}$ no es impensable que vuelva a suceder), la paralización del servicio sanitario por el colapso de los hospitales y el desabastecimiento de productos sanitarios. De modo que se cumplían tres de las situaciones que justificaban la declaración del estado de alarma. El libre ejercicio de los derechos fundamentales de los ciudadanos resultaba, evidentemente, gravemente alterado, como consecuencia de la adopción del estado de alarma, pero esa alteración derivada no podía alegarse como causa de la eventual declaración de un estado de excepción. Entenderlo así nos llevaría a concluir que siempre que se da la declaración del estado de alarma se debe adoptar inmediatamente después el estado de excepción, porque la situación derivada de la declaración del primer estado de emergencia entra en la tipificación del segundo.

La declaración del estado de alarma no sólo se ajusta mejor al presupuesto material que justifica el recurso al derecho constitucional de excepción, sino que, en el supuesto concreto que nos ocupa, ofrece un escenario temporal más amplio (no limitado a 60 días), y por ello más adecuado a la hora de adoptar medidas que permitan la recuperación de una situación de "normalidad constitucional", condicionada a la superación de la crisis sanitaria que estamos viviendo. 
La discusión dogmática aún abierta y que no ofrece conclusiones determinantes, hace imposible establecer, con arreglo a criterios objetivos comúnmente aceptados, cuando la restricción de un derecho fundamental supone la suspensión de este, y cuando se limita a ser una limitación muy severa. Plantear la reflexión en estos términos para formular el juicio de constitucionalidad del real decreto que declara el estado de alarma nos lleva al ámbito de los conceptos jurídicos indeterminados, y al escenario de la valoración de las intensidades. $Y$, al final, se convierte en un juego de apreciaciones subjetivas sobre qué medidas son 0 no suspensivas de derechos. Ello nos aleja de la seguridad jurídica y, por ello, en cierto modo también del régimen ideal del estado de derecho. Ofrecer un canon alternativo, más sencillamente aprehensible y cuya virtualidad y ventajas han sido ya verificadas en otros ámbitos materiales o por otros sistemas de justicia constitucional, me parece una opción mucho más cercana a la garantía de la seguridad jurídica.

No podemos caer en la tentación fácil de valorar la adecuación del estado de emergencia declarado, por la forma concreta de aplicación que pueda adoptar en determinadas circunstancias o por determinados agentes de la autoridad. Pueden haber existido excesos, con toda seguridad así ha sido, a la hora de asegurar el cumplimiento del confinamiento domiciliario, y esos excesos, sujetos al mismo canon propuesto para valorar el marco normativo de referencia, deben ser corregidos.

Y, por último, no estaría de más plantearse, si las circunstancias vinculadas a una crisis sanitaria de proporciones pandémicas, o a una (quizá inminente) crisis climática no exigen una revisión de la LO 4/1981, prevista en otro contexto y muy condicionada, como la redacción del art. $116 \mathrm{CE}$, a las circunstancias de cambio de régimen político en que se redactaron. En otros países de nuestro entorno no existen más categorías, dentro de los estados de emergencia, que un estado excepcional de crisis y un estado de crisis vinculado a una situación bélica (lo que nosotros conocemos como estado de sitio), y esa simplificación del modelo de derecho de excepción no impide adoptar medidas de toda índole en situaciones iguales o equivalentes a las que prevé el art. 116 CE. Quizá sería el momento de revisar nuestro derecho constitucional de excepción, teniendo presentes las lecciones aprendidas. También en relación con la inutilidad práctica de distinguir entre los conceptos de suspensión y limitación de los derechos fundamentales. 